\title{
SEARCH: A Meta-Framework and Review of the Field of Positive Education
}

\section{Waters ${ }^{1} \cdot$ D. Loton ${ }^{1}$}

Accepted: 20 June 2019 / Published online: 26 July 2019

(C) The Author(s) 2019

\begin{abstract}
This paper presents a data-driven, meta-framework to support evidence-based decisions for researchers and practitioners when designing, investigating and implementing positive education interventions: the SEARCH framework. SEARCH was developed through a two-stage process. Stage one comprised a large-scale bibliometric review and thematic grouping of topics based on natural language processing of over 18,403 positive psychology studies. Stage two involved action-research with ten schools testing the practical validity of the wellbeing themes identified in stage one with educators. The result of these two stages identified six overarching pathways to wellbeing that formed the SEARCH framework: 1) strengths, 2) emotional management, 3) attention and awareness, 4) relationships, 5) coping and 6) habits and goals. The aim of this current review paper was to examine the existing educational and psychology literature for evidence of whether each SEARCH pathway has been found to successfully foster student wellbeing. Seventy five peer-reviewed studies (total student $N=35,888$ ) were reviewed from North America, Europe, the United Kingdom, Asia, Australia and New Zealand. Results demonstrate the value and applicability of the SEARCH framework. The comprehensive review conducted in this paper is then used to discuss current gaps in positive education research as well as present the utility of SEARCH as a framework to support positive education science and practice.
\end{abstract}

Keywords Positive education · Student wellbeing $\cdot$ Schools $\cdot$ Frameworks $\cdot$ Mental health

\section{The Growth of Positive Education}

The term 'positive education' was coined by Professor Martin Seligman and colleagues in Seligman et al. 2009, who argued that schools should "teach both the skills of

L. Waters

L.Waters@unimelb.edu.au

1 Melbourne Graduate School of Education, University of Melbourne, 217, 100 Leicester street, Parkville, Victoria, Australia 
wellbeing and the skills of achievement" (Seligman et al. 2009, p.294). More recently, Slemp et al. (2017) defined positive education as an approach that "combines the concepts and scholarship of positive psychology with best practice guidelines from education" (p.101). These definitions highlight that positive education is an applied science that weaves contemporary knowledge from the science of wellbeing and positive psychology into educational practice with the aim of supporting student wellbeing.

While school-based mental health interventions have existed since the 1930s (Hildreth 1930; see Dawood 2013 for a review), the newer field of positive education has extended the aims beyond the reaction and prevention of illbeing to include the promotion and enhancement of wellbeing, defined by Huppert and Johnson (2010) as a state of feeling good and functioning well.

Positive education is a growing field according to two recent reviews of the positive psychology literature (Donaldson et al. 2015; Rusk and Waters 2013). Turning to the field of school psychology, Froh et al. (2011) found evidence for the widespread study of positive topics, identifying a vast array of 449 positive constructs/processes that have been empirically studied in this field. ${ }^{1}$ In line with this, Shankland and Rosset (2017) assert that "the application of positive psychological interventions in schools is a fastdeveloping area of research" (p. 364).

In addition to the growth in science, Seligman and Alder (2018) have found that positive education practice is growing globally and is being applied in schools across Bhutan, China, India, Israel, United Arabs Emirates, Kingdom of Saudi Arabia (KSA), Jordan, Australia, Mexico, Peru, North America and the United Kingdom. In Australia, Allen et al. (2017) found that mental health promotion was the second most prevalent goal of schools behind academic motivation. Over $65 \%$ of schools spoke proactively, in their mission statements, about protecting and optimising mental health through enhancing strengths and capabilities and raising positive states such as joy, happiness, vigour, optimism, kindness and meaning.

The rapid growth of positive education creates both opportunities and challenges. Certainly, the expansion has produced new science and practice about the conditions and processes that promote student wellbeing. However, challenges have arisen when navigating and integrating such a rapidly growing and vast (i.e., 449 constructs) body of work and the cumulative evidence needed to establish the generalisability of many positive education interventions is missing. For example, Froh et al.'s (2011) review found that only $13 \%$ of positive constructs/processes published were studied 10 or more times suggesting that researchers are not yet undertaking the repeated analysis needed to establish replicability. Commendable meta-analyses are emerging on specific topics (e.g., social-emotional learning, Durlak et al. 2011; mindfulness, Maynard et al. 2017), but the focus is necessarily narrow, generally tapping into only one or a small number of the constructs and not spanning the full array of the field.

The vastness of the field is confronting for schools who are left not knowing which of the hundreds of different interventions will best apply to their students. White and

\footnotetext{
${ }^{1}$ Note Froh et al. (2011) investigated the study of positive education topics in four school psychology journals (School Psychology Quarterly, Psychology in the Schools, the Journal of School Psychology, and School Psychology Review) and found a large array of positive topics but did not find a marked increase in positive education from 2000 onwards.
} 
Colleagues (White and Murray 2015; White 2016; White and Kern 2018) have argue that this can lead to ineffective, or even harmful, outcomes from well-meaning interventions. Thomas et al. (2016) ague that despite the increased interest in school wellbeing, the field lacks conceptual clarity and has failed to develop useable policies and frameworks which has led to a "fragmented approach to implementation that is inconsistent with current best-practice knowledge" (p. 507).

The question arises as to how we can facilitate the growth of positive education in a way that supports the key audiences in positive education: scholars and practitioners. The ability to meaningfully integrate science into comprehensive and testable models of student wellbeing seems the next logical step for evolving the science. Additionally, as White and Kern (2018) argue "alongside empiricism, a clear valuing of the practical application by educators is needed" (p. 2). Borrowing from the call of Thomas et al. (2016) we argue the development of a meta-framework can assist both scholars and practitioners to develop effective positive education interventions.

\subsection{The Need for Meta-Frameworks in Positive Education}

Successfully building wellbeing in students is not simply a matter of delivering a oneoff positive education intervention. Rather, an embedded approach across interconnected systems throughout a whole school is needed (Waters 2011; White and Murray 2015). A meta-framework can give researchers and practitioners a purposeful direction within which to design, apply and evaluate interventions. Such a framework must have broad and generalizable parameters that reflect a comprehensive model of student wellbeing, while still offering the flexibility needed to choose and/or design interventions that are best suited for different contexts.

By definition, a higher-order construct is made up of many lower-order factors. Applying this logic to a positive education framework, schools can build the higherorder dimensions of wellbeing through the flexible delivery of a raft of interventions that tap into and build of the sub-components of wellbeing. For example, many researchers have argued that emotional management is a higher-order dimension of wellbeing (Nathanson et al. 2016; Rivers et al. 2013). This higher-order aspect can be developed through a range of specific and concrete interventions helping students to develop emotional skills such as savouring, gratitude, body checks, breathing, mood mirroring, and so on. Over time, accumulation of these more concrete, lower-order skills builds the higher-order capacity of emotional management, a core aspect of wellbeing. The development of a positive education meta-framework will, therefore, assist scholars and practitioners to bring together the range of different interventions and deliver them in ways that cohesively build the higher order 'pathways' to wellbeing, thus addressing the criticism of Thomas et al. (2016) of fragmentation and assuaging the concerns of White and Murray (2015) and White and Kern (2018) of interventions being ineffective or harmful.

In addition to its higher-order comprehensive nature, if a meta-framework is going to be useful in advancing positive education it must be evidence-based and actionable. Thankfully, the field has amassed a decent preliminary evidence base on effectiveness to draw upon (see Waters 2017, for a recent review of the field). At its core, positive education is an applied science, meaning much of the knowledge is based on the praxis of wellbeing theories, applied in the form of interventions, to naturalistic, school-based 
settings. The focus falls on the applied end of the basic-applied research spectrum. Resultantly, a meta-framework must be useful in supporting the decision making of educators and practitioners applying positive education knowledge and interventions in concrete ways with students.

Consistent with leading thinkers in the field who assert that wellbeing is a multidimensional construct, and that students need to have the opportunity to develop a diverse range of skills to build wellbeing (Diener et al. 1999; Forgeard et al. 2011; Keyes and Annas 2009), a meta-framework must be multidimensional.

Currently, the majority of frameworks in positive education are not multidimensional but, rather, focus on only one or two aspects of wellbeing. For example, the Ruler Framework (Hagelskamp et al. 2013) focuses on building emotional intelligence, the Penn Resiliency Program focuses on resilience (Brunwasser et al. 2009) and the Collaborative for Academic, Social and Emotional Learning (CASEL) Framework (2017), focuses on developing social and emotional skills. While these frameworks are evidence-based and actionable, and each have various sub-elements of their core focus, they do not comprehensively represent the wide range of factors in the literature that comprise wellbeing. Chodkiewicz and Boyle's (2017) recent review of positive education criticizes the field for relying on single or dual frameworks arguing that these frameworks limit "the number of possible techniques and skills accessible to each student" (p. 74).

Although there are several multidimensional frameworks of wellbeing in the broader field of positive psychology (see Slemp et al. 2017 for a review of multidimensional frameworks), arguably the most popular framework is Seligman's (2011, 2018b) PERMA: positive emotion, engagement, relationships, meaning, and accomplishment. Two notable schools, St Peter's College, Adelaide (White and Murray 2015) and Geelong Grammar School (Norrish 2015), have adopted PERMA as their overarching positive education framework (note that Geelong Grammar added the sixth element of positive health).

Highlighting the importance of multidimensionality, St Peter's College empirically tested the PERMA framework with a sample of over 500 male students. The crosssectional study conducted by Kern et al. (2015) found that each element of PERMA differentially related to a range of wellbeing outcomes. For example, while positive emotion and relationships were related to life satisfaction, hope and gratitude, only positive emotion was related to student's physical vitality, and only relationships was related to spirituality. The researchers concluded that "assessing subjective wellbeing across multiple pathways offers the potential for schools to more systematically understand and promote wellbeing" (p. 262).

\section{Introducing the SEARCH Framework}

It is clear that positive education will benefit from the development of meta-frameworks to guide research and practice. To this end, the first author of this paper has been involved in a multi-year programme of research to develop a data-driven, metaframework in positive education - the SEARCH framework. SEARCH has been developed to help researchers organize current scientific findings and to advance future research. The framework is also designed to help school leaders, teachers and practitioners to make evidence-based decisions when implementing education interventions. 
SEARCH is a new meta-framework that is higher-order in nature, evidence-based, actionable and multi-dimensional. SEARCH was developed through two key stages of research. Stage one involved a large-scale, 'birds-eye', review of the science of positive psychology in order to determine the key pathways of positive functioning/ wellbeing (Rusk and Waters 2015). Stage two involved road testing the pathways identified in stage one via action research in ten schools. Both of these stages will be now be described.

With regard to stage one, Rusk and Waters (2015) applied the statistical techniques of cluster and co-term analysis to synthesize constructs emerging from 18,403 positive psychology studies published across an 18-year time frame. This large-scale, 'big data' bibliometric analysis investigated the way positive psychology constructs can be grouped in meaningful domains, and how they relate to positive psycho-social functioning (see Rusk and Waters 2015, for a detailed description). Findings revealed five over-arching pathways: 1) virtues and relationships, 2) emotional management, 3) attention and awareness, 4) comprehension and coping and 5) habits and goals. These five pathways formed the first iteration of the positive psychology (PP) framework. ${ }^{2}$

The reader can find a full description and definition of these five pathways in Rusk and Waters (2015), but in laymen's terms, the framework suggests that building wellbeing is influenced by how we relate to others (virtues and relationship), how our emotions filter our experiences (emotional management), what we focus on (attention and awareness), how we perceive and react to the world (comprehension and coping) and what we are motivated to do and achieve in life (habits and goals).

After the five pathways were identified and published, the first author of the current paper set about stage two of the framework development by examining the utility of the pathways in education through an action-research project with 10 schools. The initial framework was well received by schools, however through the action research cycle, school leaders identified three changes to the framework. First, the teachers reported that they would prefer to turn the pathway that combined virtue and relationships into two pathways, one for relationships and another for virtue. Teachers felt that the combination of relationships and virtues made it difficult for them to educate about the development of virtues that were not strongly relational in nature, such as wisdom-related virtues (e.g. open mindedness, critical thinking, problem solving) and temperance-related virtues (e.g., self-regulation). The separation of virtue and relationships into two pathways assisted schools to build these two aspects of wellbeing in more dedicated ways (see Waters et al. 2017, for the discussion of evolving from five to six pathways).

Second, feedback from students communicated that the term 'virtues' did not resonate with them and that they felt it was old-fashioned and/or judgemental. Additionally, the administrators in the public schools reported that the term virtue had parochial and religious overtones that were not suitable for their context. To make this change, Waters returned to the original 2015 database of terms and examined the literature for potential alternatives that would reflect the nature of this pathway but have more resonance with students from diverse backgrounds. Strengths was a key term used within the data base. According to Peterson and Seligman (2004), strengths are the way virtues are put into action. As such, the virtue factor was renamed strengths. Students reported that they related to, and better understood, the term strengths rather

\footnotetext{
${ }^{2}$ Initially called the Pathways of Positive Functioning Framework.
} 
than virtues and, given that strengths have an established evidence-base in positive education and are actionable (criteria listed above for positive education meta-framework), this term was adopted for the framework.

Third, the word comprehension was removed from the coping pathway based on both teacher and student feedback. This decision was made essentially for parsimony reasons. Comprehension of the situation is implied within the skill of coping and is in a way redundant. Moreover, students felt it was a very dry word that made them think of academic learning/understanding and this made the wellbeing framework less appealing to them.

This process demonstrates the differences that may emerge across different analysis methods (natural language processing of literature), to theoretical considerations and the perspective of practitioners. At the completion of stage one and two the six pathways comprising the framework were established. By taking the first letter of each pathway, the acronym SEARCH was created, and Fig. 1 visually depicts the six pathways of the SEARCH positive education framework.

\subsection{SEARCH: A Systematic Review}

Following the development and refinement of SEARCH as a meta-framework for positive education, the focus of the current paper is to conduct a systematic review of the educational literature to examine evidence of the six pathways in student samples and consider the ways these pathways can be increased in students through existing school-based interventions to boost wellbeing and academic achievement.

The current review paper was guided by the three below questions, for each of the six SEARCH pathways.

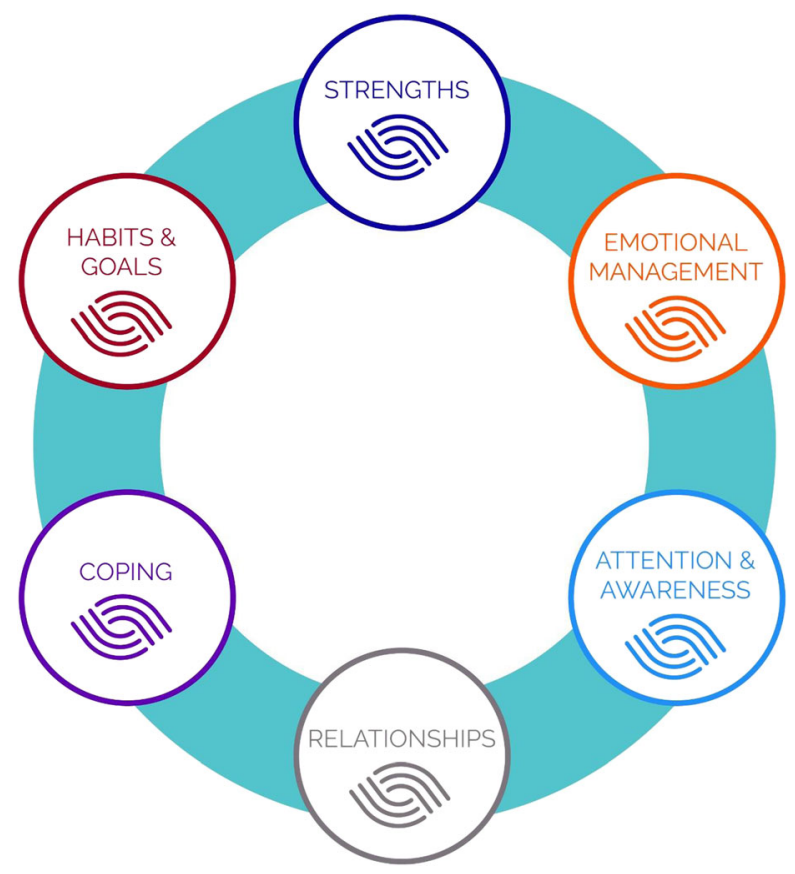

Fig. 1 Six pathways of the SEARCH framework 
1) What evidence is there to indicate that the intervention boosts the pathway it is targeting? For example, do mindfulness interventions actually boost attention and awareness?

2) What evidence is there to indicate that the intervention builds wellbeing?

3) What evidence is there to indicate that the intervention improves school-based and academic outcomes?

\section{Method}

\subsection{Identifying Relevant Articles}

To uncover peer reviewed research on school-based positive education interventions, a systematic literature search was conducted using the four databases of: Scopus ${ }^{\circledR}$, Google Scholar, PsycINFO®, and Web of Science ${ }^{\circledR}$. Additionally, the reference lists of review articles that were identified through the above search were cross-checked using the ancestry method outlined in Lyubomirsky et al. (2005), in order to capture the broadest collection of relevant articles possible.

To qualify for inclusion, studies had to meet eight key criteria. First, the study had to be peer-reviewed and published in an academic journal and, thus, have withstood the scrutiny of the peer review process. Second, the paper had to be an intervention study (studies that took measures at a single time point were excluded). Third, the study had to be field research and be implemented in schools ${ }^{3}$ rather than a laboratory or other setting. Fourth, the study had to be quantitative (qualitative studies were excluded from this literature search). Fifth, the study had to be evaluated using valid and reliable measures whose psychometric properties had been established in past research. Sixth, the study must be a primary source or original work. Seven, the sample of students had to be in mainstream schooling and functioning in the normal range of psychological health. ${ }^{4}$ Eight, we reviewed single-focus interventions within each of the six pathways. Dual or multi-dimensional program such as social-emotional (SEL) programs were not included. This decision was made so that we could establish if each separate SEARCH pathway has evidence of effectiveness in its own right, before assessing additivity, which is a logical next step for future research. As such, although multi-component programs do fit within two of the SEARCH pathways (e.g., SEL programs tap into the SEARCH pathways of emotional management and relationships) and can be used by schools to help build the six pathways of wellbeing in students, they were not included in the current review paper.

Seventy-five school-based positive education intervention studies were identified as meeting the criteria above and form the basis of this review. Table One provides definitions of the six SEARCH pathways and lists the sub-categories of interventions that were identified in each pathway for the current review. The studies qualifying for this review paper came from schools in North America (USA and Canada), Europe

\footnotetext{
${ }^{3}$ The search included samples in elementary, middle and secondary schools. Tertiary education institutions were not included.

${ }^{4}$ Studies that focused exclusively on minority samples, students with social-emotional-behaviour disturbances, trauma or clinical disorders were excluded given that the purpose of this paper is to establish SEARCH as meta-framework applicable to the general population.
} 
(Denmark, Finland, Germany, Greece, Lithuania, Netherlands, Norway and Spain), Asia (China, Tiawan), UK, Australia and New Zealand. School type ranged across public, private and parochial/religious schools as well as co-education and single sex schools. The 75 studies included a total of 35,888 students. Table two presents the details of the 75 studies including the author, country of study, sample size, details of the intervention and study design.

For consistency across the presentation of the review findings, the same structure has been used when mapping each of the six pathways to the studies identified. First, the specific interventions that can be mapped to each pathway are identified. For example, under the pathway of attention and awareness, the specific interventions identified in the school-based interventions were mindfulness and meditation. Second, the combined demographic information across the studies was reported as pertaining to school level (primary/secondary), country of study, sample size, age groups of students, study design and place of intervention (e.g. classroom or before/after school) are reported. A summary of the of the 75 studies, mapped to the six pathways, is provided in Tables 1 and 2.

Finally, and most importantly, the evidence supporting each pathway is considered. This evaluation is structured around the three key research questions listed in the former section and considers how the evidence meets Seligman et al.'s (2009) broad aims of positive education: to improve both wellbeing and academic outcomes.

\subsection{Pathway One: Strengths}

One of the major topics of study in PP is that of strengths which are defined as "preexisting qualities that arise naturally, feel authentic, are intrinsically motivating to use and energizing" (Brdar and Kashdan 2010, p. 151). Peterson (2006) argued that we should develop and use as many strengths of character as possible in schools. Benninga et al. (2006) contend that school curriculum can be used to "form the character of the young people through experiences affecting their attitudes, knowledge, and behaviours" (p. 449). White and Waters (2014) described how strengths can be embedded into student life in schools.

We obtained seven intervention studies $(N=4391, n=1766$ control, $n=1852$ intervention) that investigated the influence of character strengths programs upon the wellbeing of students. Programs ranged in content from interventions that target a broad host of strengths, to those that target one specific strength (e.g., hope). The most popular, broad strengths taxonomies in the literature identified were the Values in Action (VIA) and the Gallup Strengths Finder. The selected strengths-based interventions were geographically diverse, being undertaken in the US $(\mathrm{k}=2)$, Portugal $(\mathrm{k}=1)$, Australia $(\mathrm{k}=1)$, Israel $(\mathrm{k}=1)$, New Zealand $(\mathrm{k}=1)$ and the UK $(\mathrm{k}=1)$, with student ages ranging from 10 to 15 , total sample sizes from $N=38$ to 2650 , with all the interventions delivered in class and a preponderance of RCTs, some longitudinal, and some quasi-experimental and within-subject designs.

Do Strengths Interventions Improve Strengths Knowledge and Strengths Use? Three intervention studies answered this question. First, the Strath-Haven Positive Psychology program (Seligman et al. 2009) used Peterson and Seligman's (2004) VIA framework to encourage students to identify their signature character strengths and 


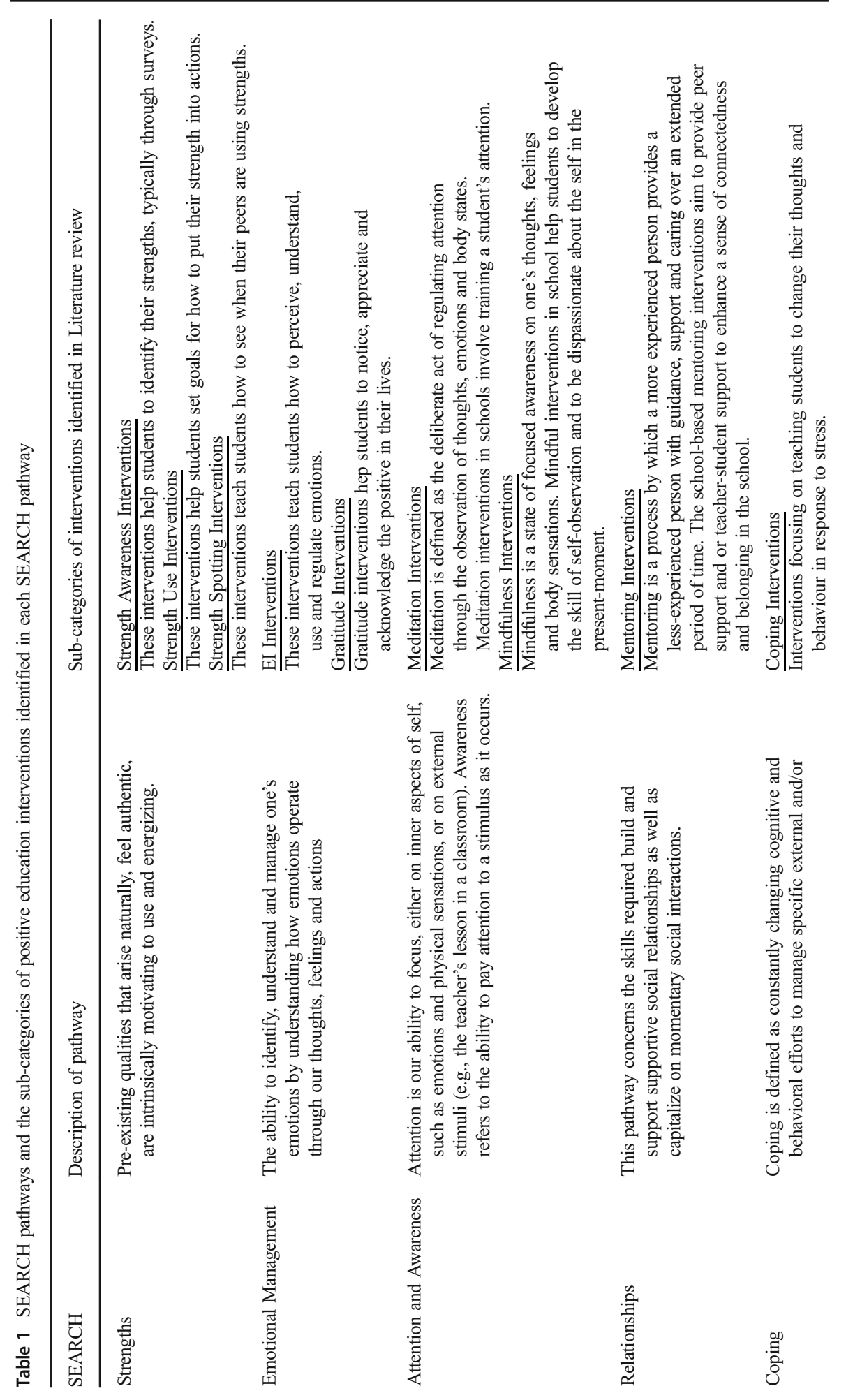




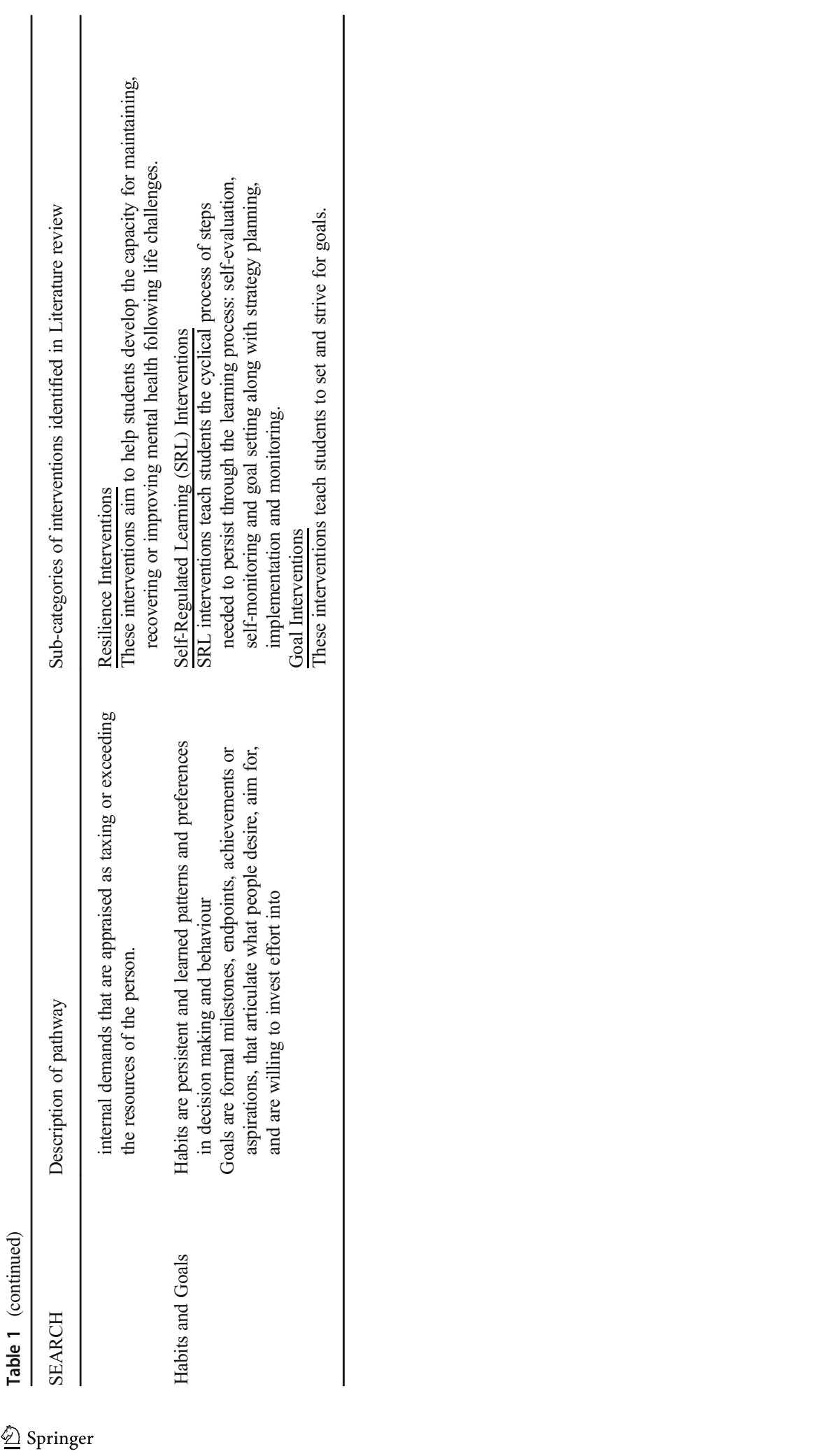




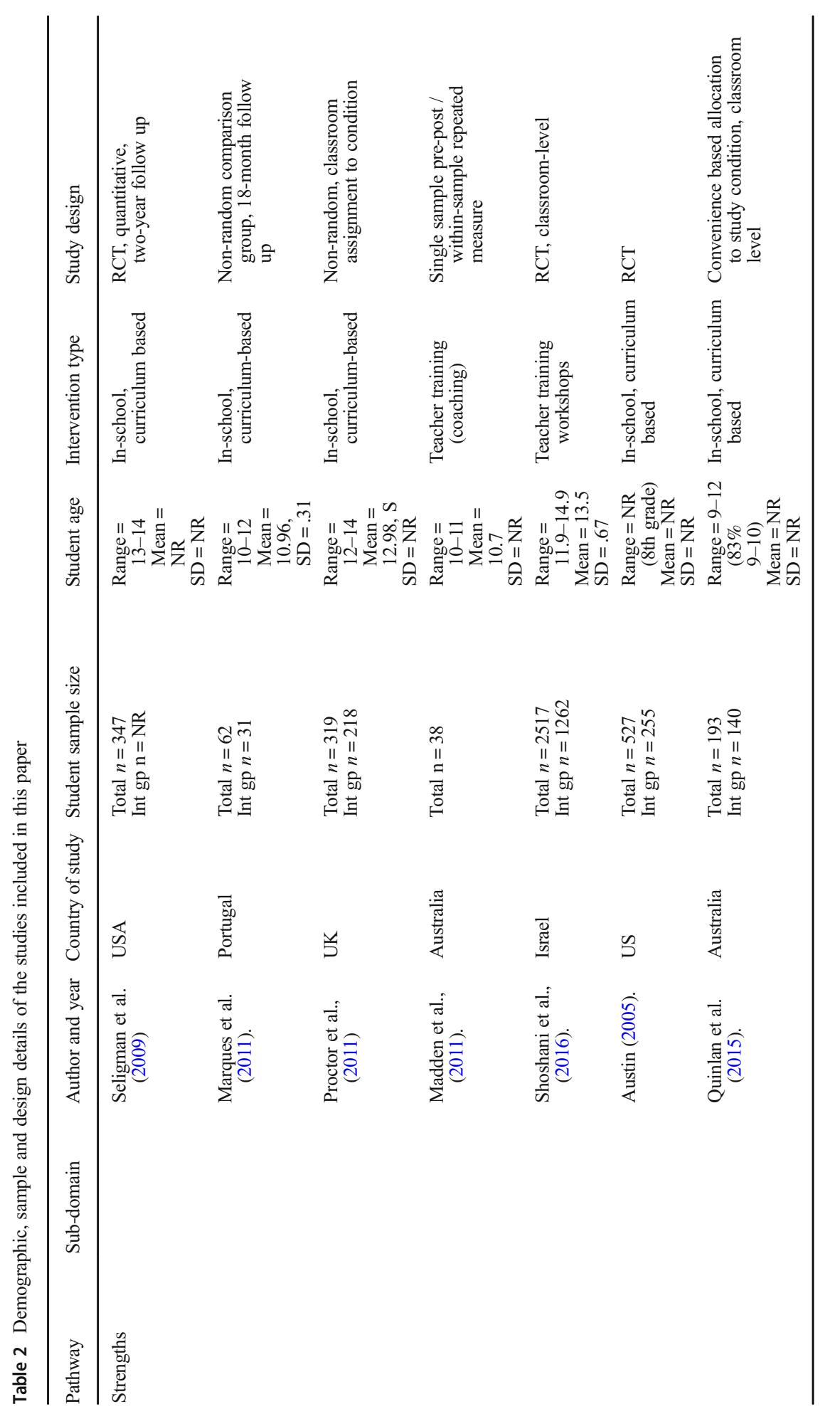




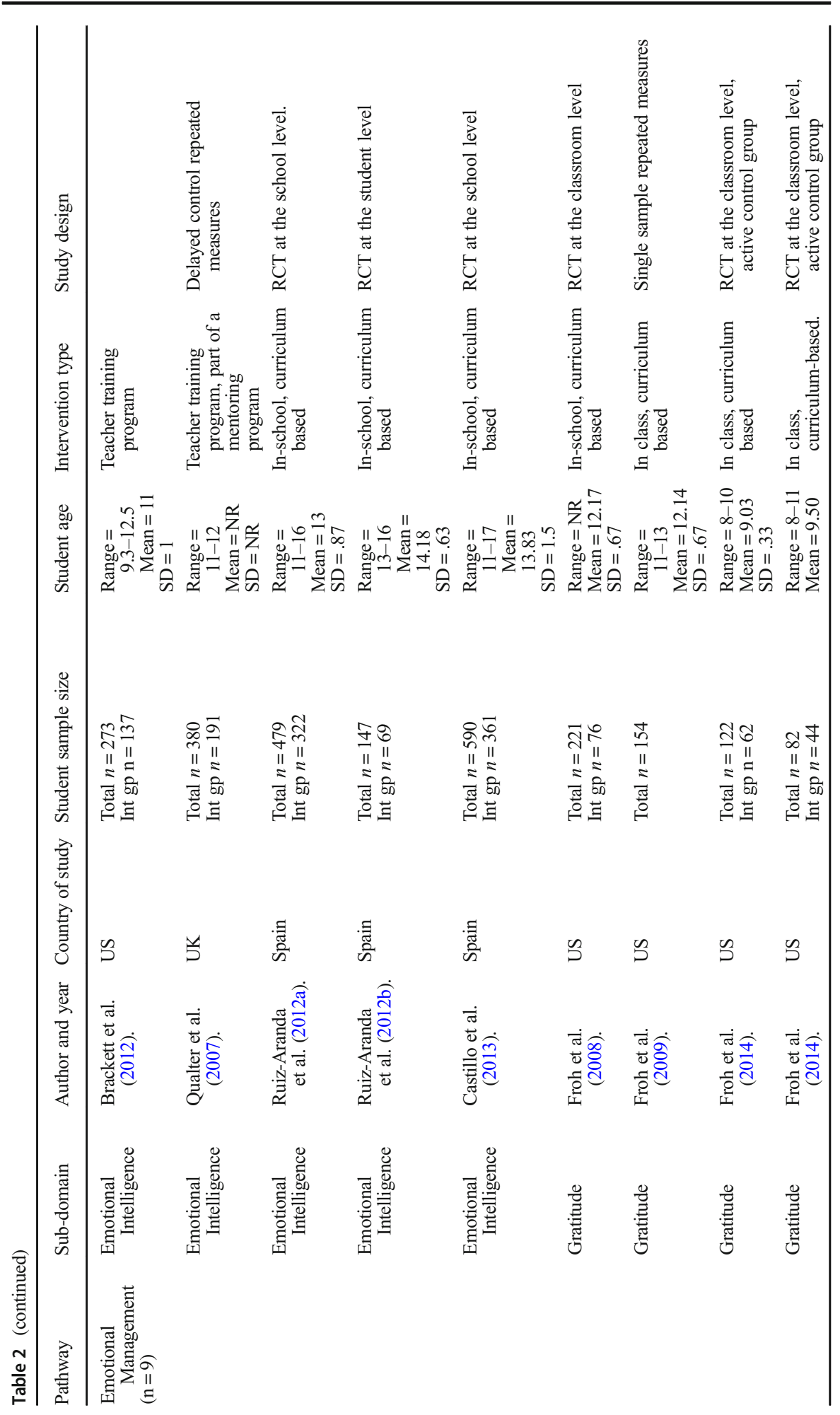




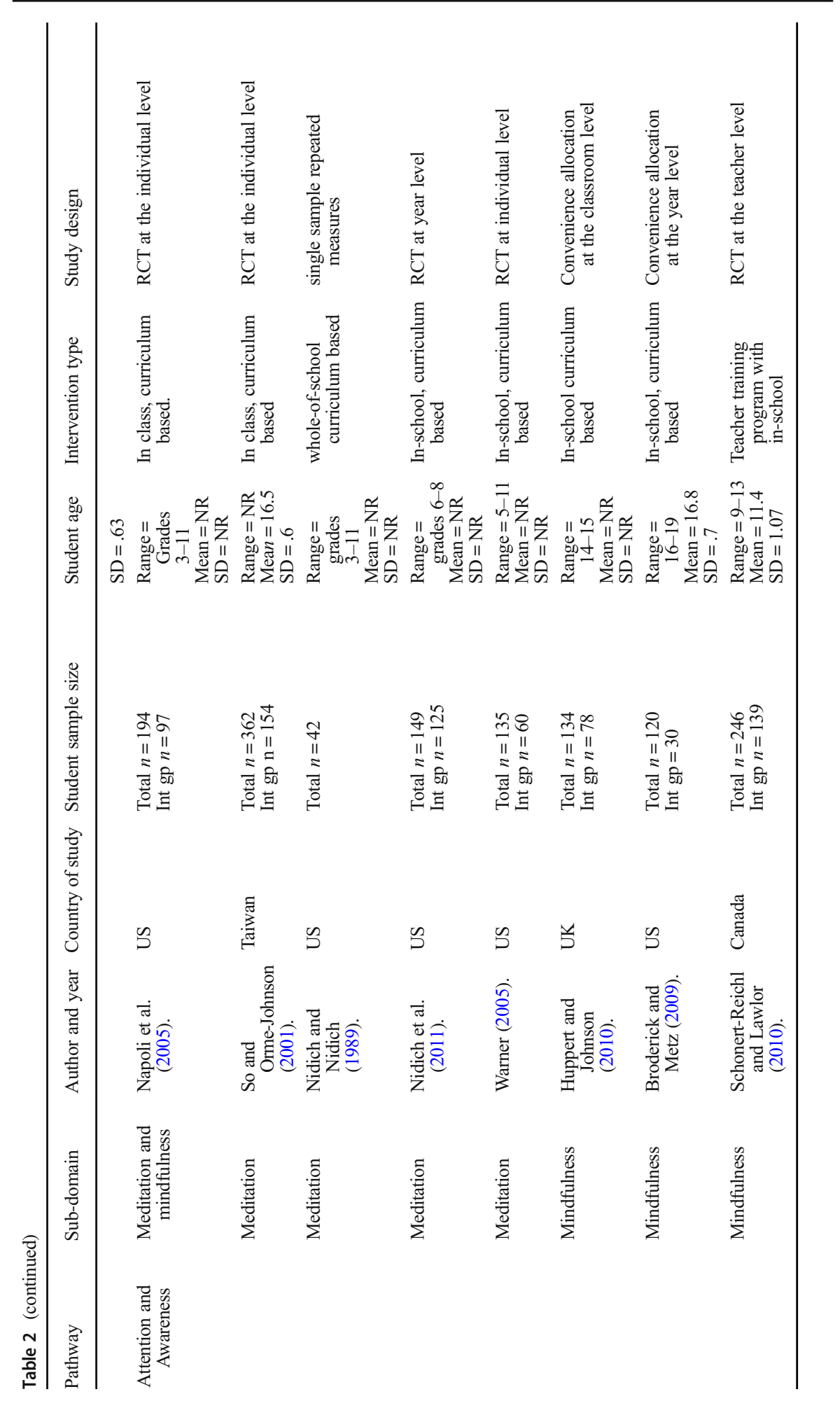




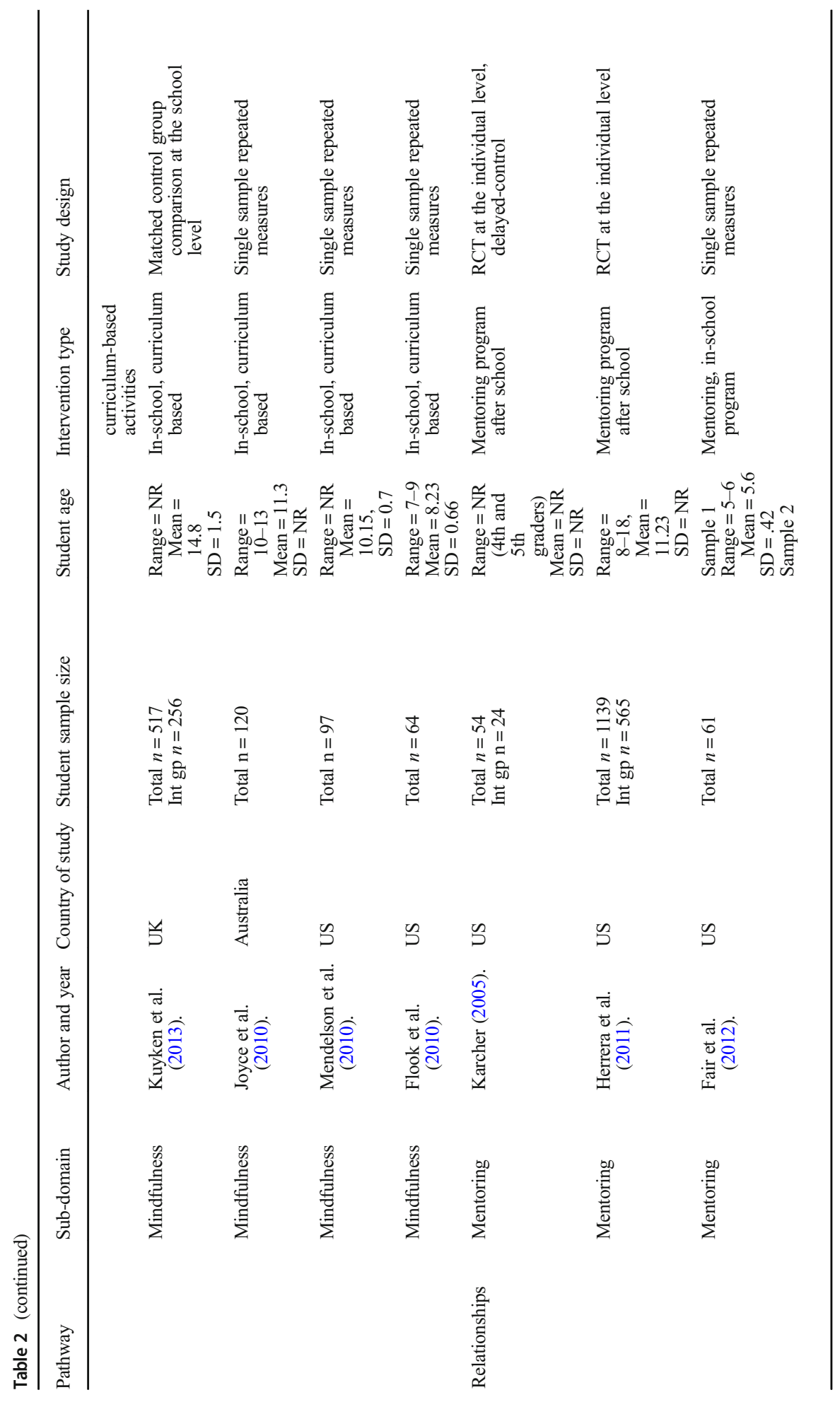




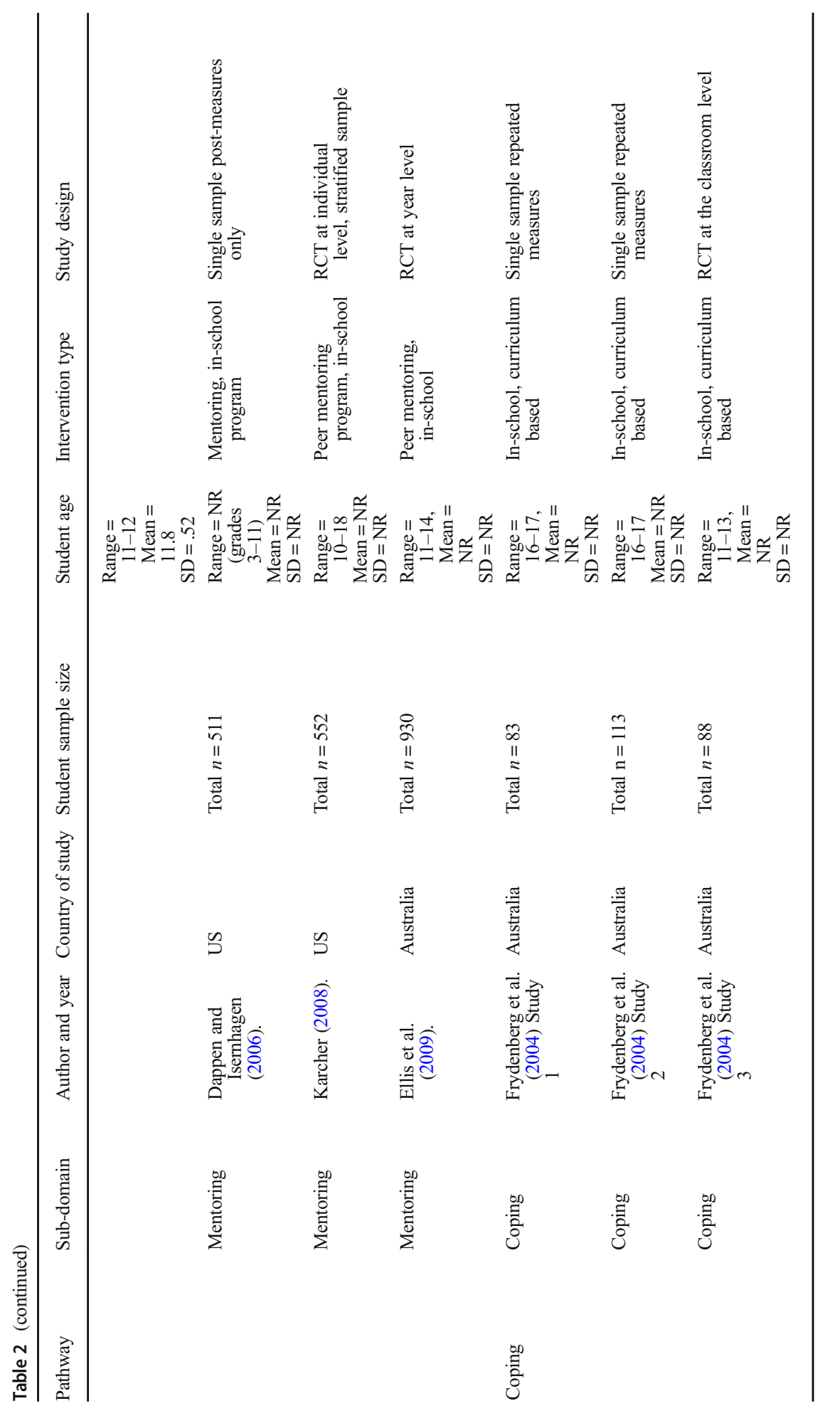




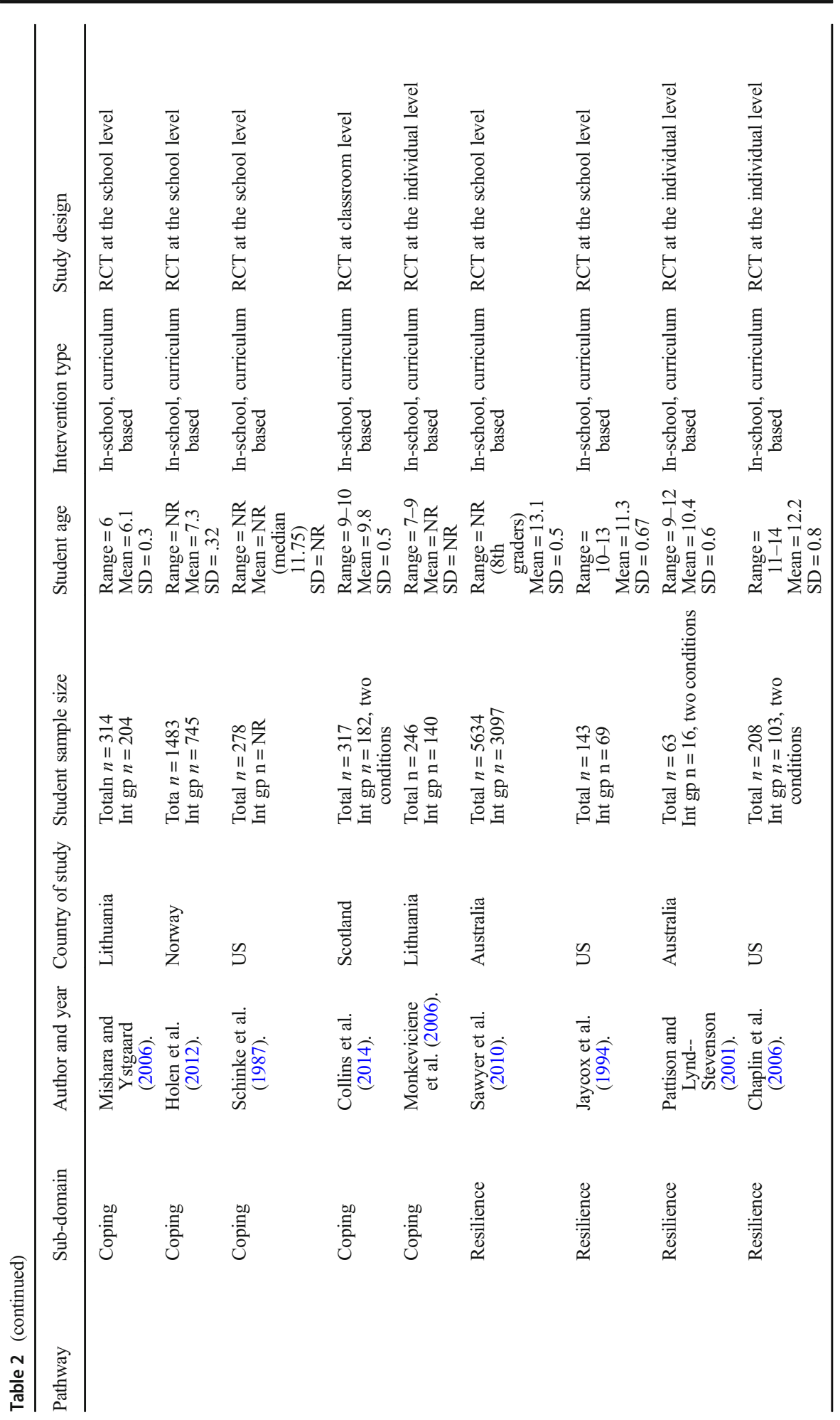




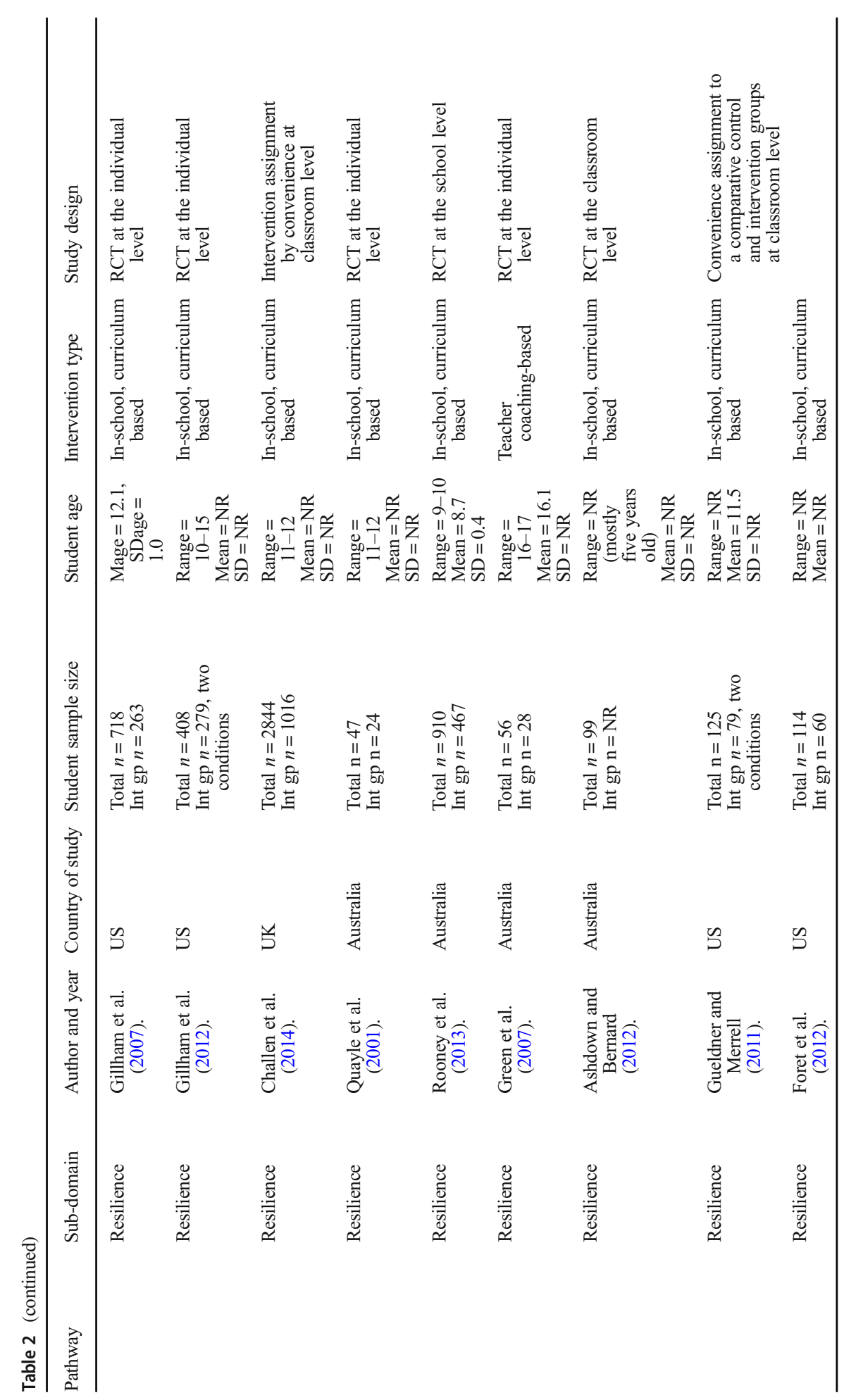




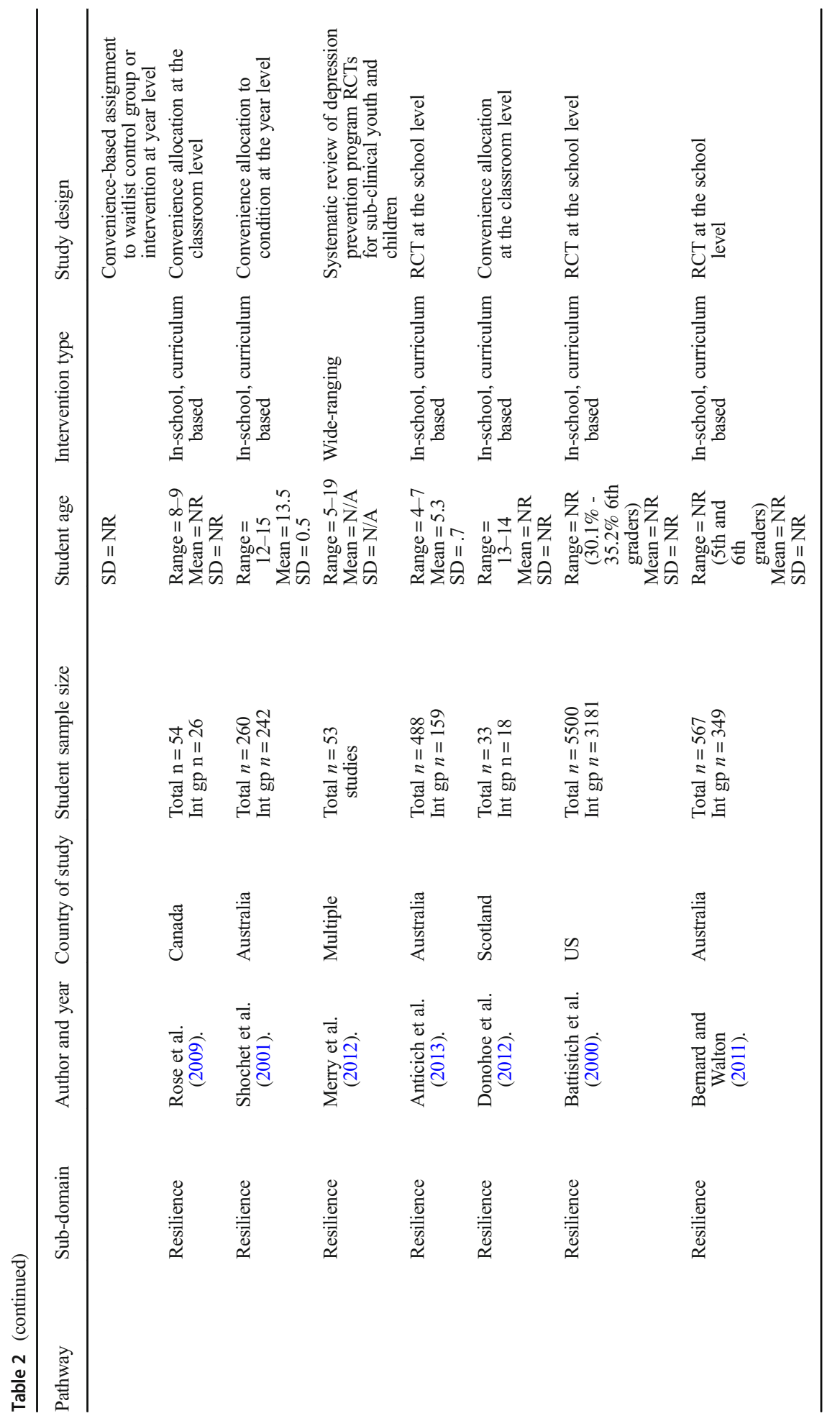




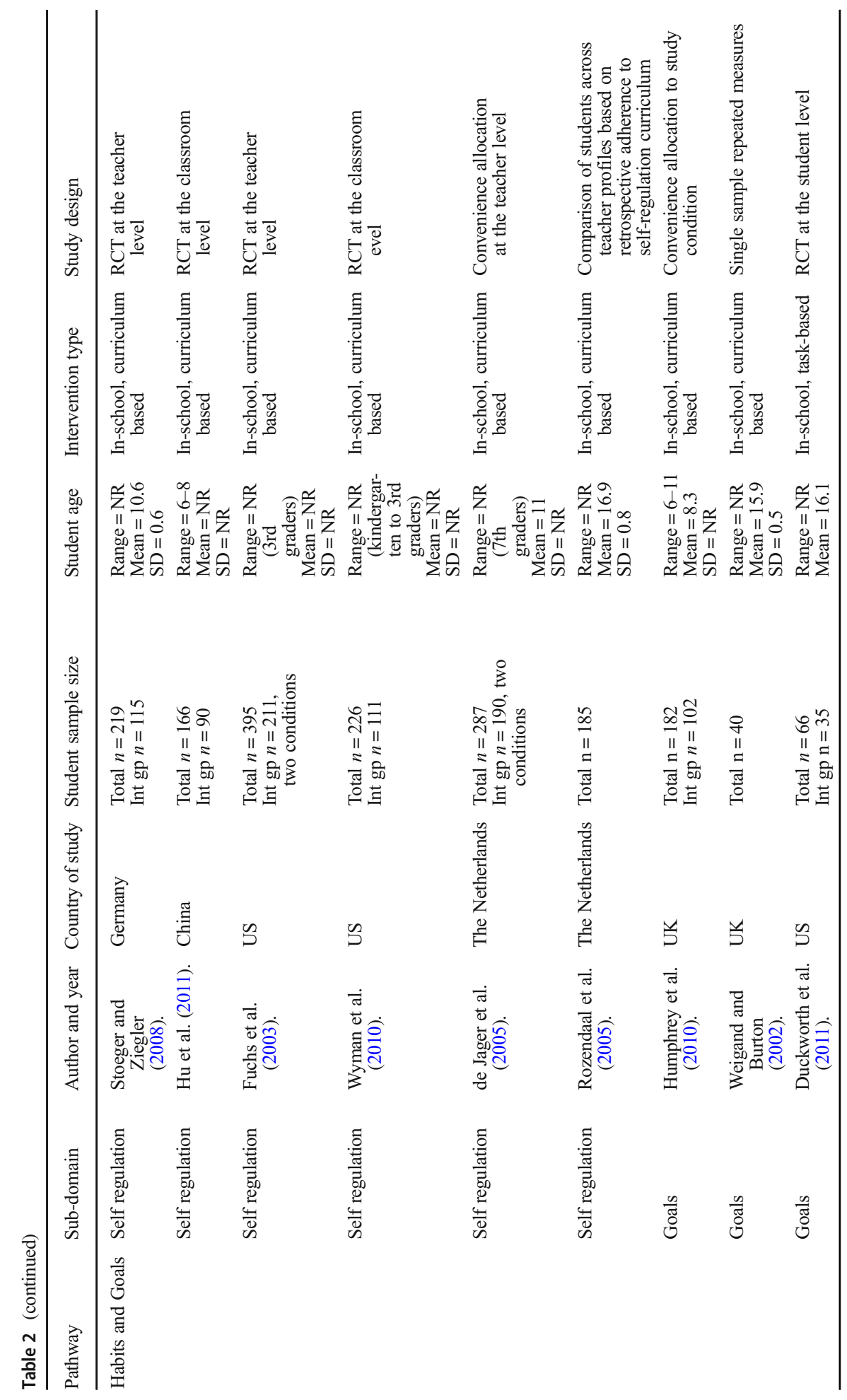




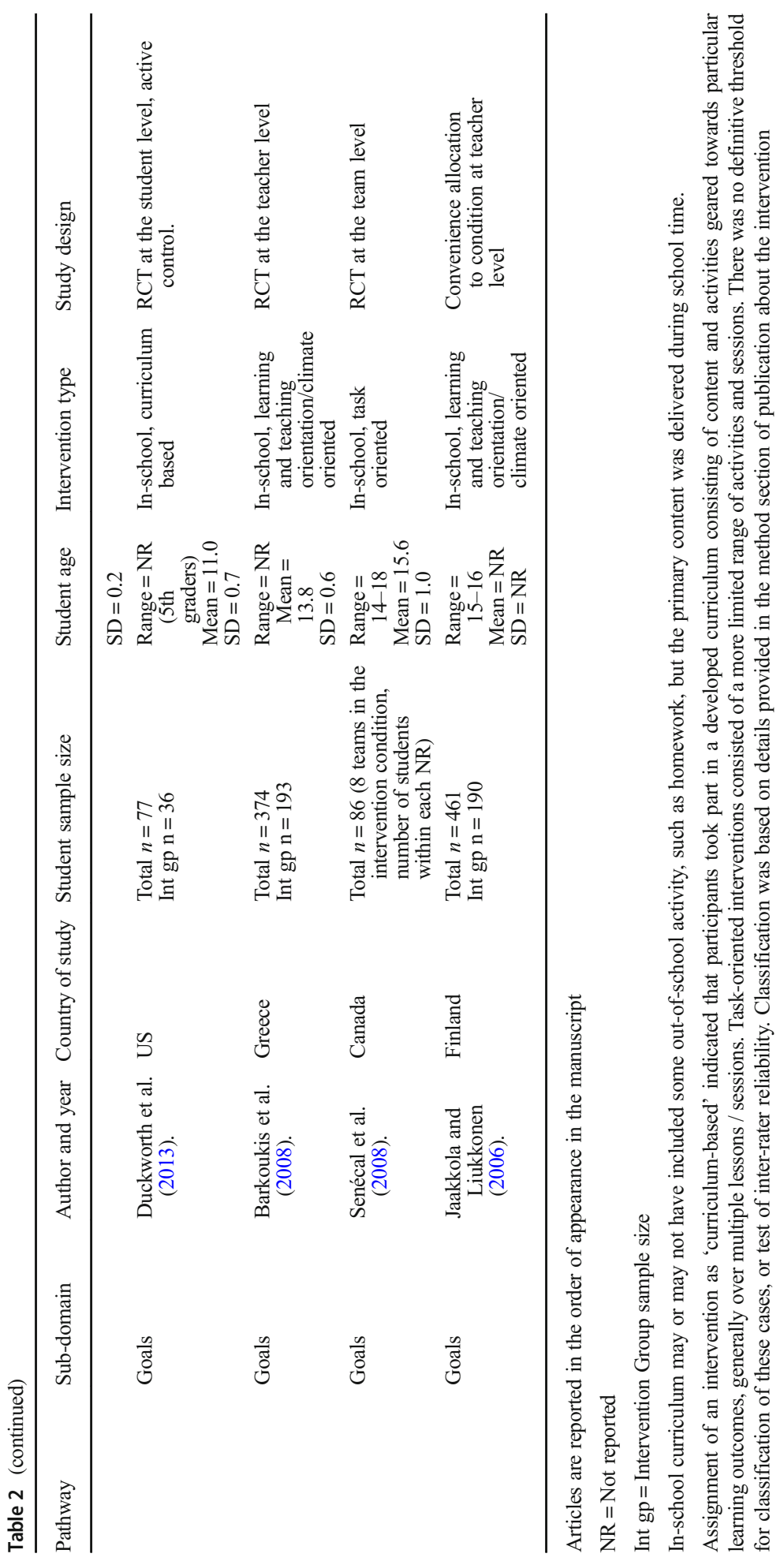


increase their use in daily life. Teacher reports and self-reports comparing pre-test to post-test and between group comparisons revealed that the programme improved a subset of particular strengths that related to learning such as the strengths of curiosity, love of learning, and creativity. Quinlan et al. (2015) examined the effect of a classroombased strengths intervention and reported that students learned to recognise their strengths and practise their strengths through strength-related goal setting over a three-month time frame. In a five-week intervention on the specific strength of hope in middle school students, Portugal, Marques et al. (2011) found significant increases in self-reported student levels of hope.

Do Strengths Interventions Improve Wellbeing Outcomes? There were five strengths interventions that looked at wellbeing outcomes for students. Proctor et al. (2011) examined the impact of Strengths Gym, based on the VIA framework, and found that adolescents who participated in the character strengths interventions experienced significant increases in life satisfaction and positive affect from baseline to post-test accounting for baseline levels of life satisfaction, age, gender, and academic performance. Madden et al. (2011) designed and evaluated a strengths-based coaching program for primary/ elementary school children and reported increases in hope and engagement. However, the study did not use a control group and so the authors cannot suggest causal interpretations.

In Israel, Shoshani et al. (2016) conducted a large-scale, multi-year randomized controlled trial that that had a strong emphasis on character strengths. The authors reported significantly larger growth in the intervention versus control group in emotional subjective wellbeing, peer relations and emotional engagement. However, growth curve analysis revealed some reversion in these gains in the second year of the program, which would not be inconsistent with a reversion to time-invariant averages specific to each person, in many measures of subjective wellbeing.

As discussed in the former section, Marques et al. (2011) investigated the effectiveness of a five-week hope intervention and found the intervention group had significantly enhanced levels of life satisfaction and self-worth. These benefits were maintained at the 18-month follow up. This study demonstrates that interventions focusing on one character strength can be effective in increasing student wellbeing over time. The matched nature design of the study groups reduces the influence of demographic imbalance between sample groups from impacting the results; however the small group sizes limit the extent to which the findings can be generalized to a wider population.

When it comes to the effect of strengths interventions on reducing negative indicators of mental health in students, the research is not strong. Proctor et al. (2011) found no impact of their strengths intervention on students' levels of negative affect. Similarly, Seligman et al. (2009) found no significant declines in anxiety and depression as a result of the Strath-Haven Positive Psychology program. Hence although school-based strengths interventions are having significant effects on certain positive aspects of wellbeing (e.g. life satisfaction, self esteem, positive affect), they have not been shown to diminish negative symptoms such as anxiety, depression and negative affect.

Do Strengths Interventions Improve School-Based and Academic Outcomes? There are six intervention studies that have looked at the effect of strengths programs and academic outcomes. Using the Gallop strengths framework, Austin (2005) compared educational outcomes of students who were randomly assigned to a 6-week strengths 
program with students in a standard curriculum control condition and showed that, after completion of the strengths program at school, students in the strengths group had significantly higher academic expectations, academic motivation, and perceptions of academic ability as compared to the control students. The use of a control group in the study design provides some evidence of a causal influence between the understanding and use of character strengths and a variety of positive learning outcomes for students.

Shoshani et al.'s (2016) evaluation of a multi-year and multicomponent positive education strength-based program reported significant gains after a year in the outcome measures of cognitive engagement, and grade point average (GPA). Effect sizes were moderate, and the program resulted in an average gain of $7 \%$ in standardized academic performance scores.

The Strath-Haven Positive Psychology program was found to increase student enjoyment and engagement in school (Seligman et al. 2009). Students in Madden et al.'s (2011) strengths intervention found that students showed significant improvements in engagement following the strengths intervention. However, Marques et al. (2011) did not find any significant difference in academic achievement between the hope group and the control group over time. Quinlan et al.'s (2015) classroom-based strengths intervention also reported significant improvements in student's classroom engagement, while controlling for baseline between-group differences.

Summary of Strength-Based Interventions In sum, the results from the seven evaluations show that character strengths can be explicitly taught in schools and can boost strengths such as curiosity, creativity, love of learning and hope. The results also show that when character strengths are included in the curriculum students benefit from higher levels of wellbeing although, as yet, not lower levels of illbeing. There was some evidence of stronger academic outcomes arising after students go through a schoolbased strengths intervention such as higher engagement, academic confidence and academic aspirations, but this was not a universal finding and Marques et al. (2011) did not find any effect of their hope intervention on academic achievement.

\subsection{Pathway Two: Emotional Management}

The role that emotions play in learning has received considerable research interest (Pekrun et al. 2002). Whereas educationalists have traditionally viewed learning as a cognitive process, advances in neuroscience and psychology now show that learning is profoundly affected by our emotions (Immordino-Yang and Damasio 2007; Jensen 2008; Fredrickson and Branigan 2001). Indeed, the academic information that students receive in class is routed through both the rational and emotional systems in their brains, and the emotional climate of a classroom has a significant effect on the degree to which the material taught in class will be committed to memory (Jensen 2008). The ability for school programs to boost a student's emotional management have received considerable research within the umbrella of social-emotional learning.

Given that this current review was interested in reviewing evidence for each of the six pathways individually, we have not included evidence from social-emotional programs because this confounds two key pathways and does not show schools how to build each pathway separately. The wellbeing results of SEL programs are important 
and have built up convincing evidence for schools to teach SEL skills, however they do not clarify to what degree wellbeing is improved due to an increase in emotional management as separate from relationship skills (for a review of SEL programs, see Durlak et al. 2011). In the current review paper, positive education interventions were found that fall under two key constructs: 1) emotional intelligence and 2) gratitude.

Emotional Intelligence Emotional intelligence (EI) is generally understood as the ability to perceive, understand, use and regulate emotions (Brackett et al. 2012; RuizAranda et al. 2012a). EI has the potential to be taught and, as such, has become a focus for school-based interventions. With regard to EI, five studies were located for this review. Four were conducted within high schools (Castillo et al. 2013; Ruiz-Aranda et al. 2012a; Ruiz-Aranda et al. 2012b; Qualter et al. 2007) and one at a primary level (Brackett et al. 2012). Three studies were completed in Spain (Castillo et al. 2013; Ruiz-Aranda et al. 2012a, b), one in the USA (Brackett et al. 2012) and another in the UK (Qualter et al. 2007), with an overall sample size of 1828 students (1086 intervention; 742 control). The age of participants ranged from 9 to 16 years of age. All studies were quasi-experimental and involved EI interventions taking place in the classroom lasting between 30 weeks and 2 years.

Do El Interventions Improve El? Interventions in schools that focus on EI have been found to be effective in building emotional intelligence skills and in students. For example, EI intervention benefits reported by Brackett et al. (2012), showed that primary school students in intervention classrooms were given higher ratings by their teachers on emotional competence and adaptability, compared to those in control classrooms. These researchers also suggested that the success of EI interventions are influenced by the degree of EI present at baseline. Students with low baseline levels of EI and empathy showed greater increases in EI at the end of the intervention (Qualter et al. 2007; Castillo et al. 2013).

Do El Interventions Improve Wellbeing? The published EI intervention studies in this review paper also assessed the impact on various wellbeing outcomes for students. EI interventions were found to increase self-esteem and mental health as well as to reduce anxiety, depression and social stress compared to control groups (Ruiz-Aranda et al. 2012a, b; Qualter et al. 2007). In addition to intrapersonal wellbeing outcomes, EI interventions have also been found to boost interpersonal wellbeing outcomes. For example, a number of social changes were observed with Castillo et al. (2013) finding that the EI intervention group reported reduced levels of physical and verbal aggression post intervention and the Brackett et al. (2012) finding that teacher ratings of students' positive relationships in class increased post intervention.

Do El Intervention Boost School-Based and Academic Outcomes? Three of the five EI intervention studies examined the effect of the interventions on school-based and/or academic outcomes. Brackett et al. (2012) reported higher end of year grades in the EI intervention group compared to the control group. Additionally, Qualter et al. (2007) found that scholastic-confidence increased at post-test compared to the control group. Qualter et al. (2007) also found that those students who participated in the EI intervention were better equipped for their school transition from year 6 to year 7 . 
Gratitude Interventions Gratitude has been defined as "a sense of thankfulness and joy in response to receiving a gift, whether the gift be a tangible benefit from a specific other or a moment of peaceful bliss evoked by natural beauty" (Peterson and Seligman 2004 , p. 554). We identified four studies that have tested gratitude interventions ${ }^{5}$ in schools. The studies ranged across elementary, middle and high school levels, with a student age range of 8 to 19 years and a total sample size of 514 students (226 intervention, 288 comparison). All interventions took place in the US, within the classroom, and ranged from daily sessions across one or two weeks, to weekly sessions across five weeks. Three studies employed a quasi-experimental design, randomly assigning classrooms to gratitude or comparison conditions, while one study was a randomised controlled trial at the individual level. The interventions included writing about daily blessings (Froh et al. 2008), writing and delivering a gratitude letter (Froh et al. 2009), and learning about benefit appraisals ("grateful thinking"), the socialcognitive perceptions that cause gratitude (Froh et al. 2014).

Do Gratitude Interventions Improve Gratitude? Froh and his colleagues measured the effect of three gratitude interventions on student levels of gratitude. In the Froh et al. (2008) study, early adolescents who counted daily blessings reported higher gratitude than students who counted hassles, but the students in the blessings group did not differ in gratitude from no-treatment control students. Similarly, Froh et al. (2009) did not find any differences in gratitude between students who wrote and delivered a gratitude letter (intervention) and students who journaled about daily events (control) at post-test and 1- and 2-month follow-up. However, they did find that students in the intervention condition who were initially low in positive affect (PA) reported greater gratitude at post-test and 2-month follow-up, compared to those low in PA. Therefore, PA at baseline moderated the effect of the gratitude intervention.

In an intervention study of a gratitude curriculum conducted with elementary students, Froh et al. (2014, Study 1) found that students who were taught the gratitude curriculum reported significantly more gratitude at post-test and wrote more thank-you cards (a behavioural expression of gratitude) to parents who gave a presentation to the students than control students. In a second study, intervention students reported higher gratitude at 12 weeks, compared to the control group. In both studies, students also scored higher on grateful thinking after the gratitude intervention than at baseline (Froh et al. 2014).

Do Gratitude Interventions Improve Wellbeing Outcomes? With regard to wellbeing outcomes, Froh et al. (2008) found no difference in positive affect (PA) between intervention and two comparison groups across 8-day aggregate, post-test and follow-up measures. Similarly, in another sample Froh et al. (2009) found no differences in PA or negative affect (NA) between intervention and control groups. However, baseline PA again moderated the effect of the intervention, as intervention group students were initially low in PA reported greater PA at post-test and 2-month follow-up, compared to control group students who were low in baseline PA. This suggests that gratitude may be effective for enhancing PA in youth, but only for those who were originally low in PA.

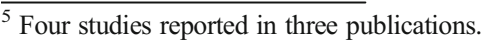


In evaluations of life satisfaction, Froh et al. (2008) found no difference between a gratitude intervention and those in a control (documenting hassles) condition. Similarly, Froh et al. (2014, Study 2) found no differences in life satisfaction between the intervention and control groups in his study with elementary students.

Do Gratitude Interventions Improve School-Based and Academic Outcomes Froh et al. (2008) found that the gratitude group of elementary students reported significantly greater satisfaction with their school experience at post-test and 3-week follow-up compared to other study groups.

\section{Summary of the Positive Education Research in the Emotional Management} Pathway Ways to boost the emotional management pathway of the SEARCH framework have been studied in schools via EI and gratitude interventions. Results show that students can increase EI and gratitude through classroom programs and practises and that these interventions are especially helpful for students who are low on these two emotional aspects. Results also show that EI interventions boost a range of wellbeing indicators such as PA, self-esteem (although not life satisfaction) as well as reducing distress indicators such as NA, anxiety, depression and stress. School and academic outcomes such as school satisfaction, scholastic-confidence, transitions from year 6 to 7 and grades were all significantly increased following these emotional management interventions.

\subsection{Pathway Three: Attention and Awareness}

Broadly speaking, attention has been defined as the ability to focus, either on inner aspects of self, such as emotions and physical sensations, or an external stimuli (such as the teacher's lesson in a classroom) (Beauchemin et al. 2008). According to Steiner et al. (2013), awareness refers to the ability to pay attention to a stimulus as it occurs. Wellbeing is aided when individuals can consciously control their attention and direct it toward particular aspects of sensory or cognitive information. The school-based interventions included in this review that relate to the SEARCH pathway of attention and awareness involve meditation and/or mindfulness.

Meditative Interventions Meditation refers to the deliberate act of regulating attention through the observation of thoughts, emotions and body states (Black et al. 2009; Zylowska et al. 2008). Six school-based meditation interventions were found for this review. Three studies were conducted in elementary schools, one middle school sample, and two middle-senior school samples. Interventions were conducted in USA $(\mathrm{k}=4)$, Canada and USA combined $(\mathrm{k}=1)$, and Taiwan $(\mathrm{k}=1)$. The sample sizes ranged from 42 to 272 with an overall sample size of 898 . Students ranged in age from 6 to 18 years. Two studies utilized randomized controlled designs and four were quasiexperimental. Five studies used transcendental meditation and one used attention training as the meditation intervention. Four of the meditation interventions took place in the classroom and two took place at the start or end of the day. The intervention lasted between three months and two years; and in one school the intervention was ongoing. 
Do Meditation Interventions Improve Attention? Even though a key aim of meditation is to teach students how they can regulate, control and focus their attention, only one of the six studies included a direct assessment of attention. In a randomized controlled study in a primary school sample, Napoli et al. (2005) asked teachers to score three attentional measures that assessed students' selective attention (ability to direct attention to a particular stimuli) and sustained attention (ability to keep focused over time) before and after the intervention. In comparison to the students in the control group, teacher ratings on attentional ability for students who underwent the meditation intervention showed significant improvements. But, aside from this one study, there is no other evidence to show that school-based meditation interventions enhance a student's attention skills.

Do Meditation Interventions Improve Wellbeing Outcomes Two of the five studies considered the effect of meditation interventions on wellbeing. Napoli et al. (2005) and So and Orme-Johnson (2001) both found that state anxiety and trait anxiety reduced after the meditation intervention compared to control groups. In addition, Napoli et al.'s (2005) study showed that teacher ratings of students' social skills increased from before and after the program for the intervention group but did not change for the control group.

Do Meditation Interventions Improve School-Based and Academic Outcomes? Using standardised tests as outcome variables, Nidich and Nidich (1989) and Nidich et al. (2011) provide strong evidence of the impact of transcendental meditation (TM) programs on academic performance. Nidich and Nidich (1989) examined the impact of 12-min sessions of TM on academic achievement, and found that third- to seventhgraders demonstrated an increase in reading, vocabulary, language and study skills, while ninth- to eleventh-graders improved on social studies, literary materials, reading and quantitative thinking skills on Iowa Tests of Basic Skills (ITBS) and Iowa Tests of Educational Development (ITED) tests. Nidich et al. (2011) reported strong significant improvements in English and Math scores on the California Standards Test for students who underwent three-months of twice-daily (i.e. before and after school) 12-min TM practice in comparison to a randomly assigned control group.

Other evidence for the relationship between meditation interventions and academic outcomes was found by Warner (2005) who showed that those students who received awareness training performed at a higher level than controls on various cognitive functioning tests of working memory, reflectivity, flexibility, and conservation.

Mindfulness Interventions Mindfulness is defined by Kabat-Zinn and Santorelli (1999) and Kabat-Zinn (2003) as a state of present-moment awareness that emerges through paying deliberate attention, without judgement, to one's moment-by-moment experiences. It is a state of focused awareness on one's thoughts, feelings and body sensations as these phenomena unfold and can, thus, be understood as a type of self-observation that is dispassionate and present-focused (Sedlmeier et al. 2012).

Seven school-based mindfulness studies fit the criteria to be included in the current review paper. One study was conducted in elementary school, four at middle school and two at the secondary level. The interventions were conducted in USA $(k=3)$, UK $(\mathrm{k}=2)$, Canada $(\mathrm{k}=1)$ and Australia $(\mathrm{k}=1)$. The sample sizes ranged from 64 to 246 with the overall sample size of 671 students participating on these studies. Three studies 
were randomized controlled design and four were quasi-experimental and involved mindfulness interventions taking place in the classroom, lasting between 4 weeks and 12 weeks.

Do Mindfulness Interventions Improve Attention? Two of the seven studies directly assessed attention in the school-based mindfulness interventions using either student ratings or teacher ratings. Huppert and Johnson (2010) found that students self-reported ability to regulate attention and be aware of experience did not, on average, improve after a mindfulness program. However, the degree of mindful practice was a moderator, with increased practice at home predicting higher self-rated ability to regulate attention and be aware of experience. Using teacher reports, Schonert-Reichl and Lawlor (2010) found teacher-reported ratings of in-class attention and concentration improved for the intervention group relative to control.

Do Mindfulness Interventions Improve Wellbeing Outcomes? The mindfulness interventions reviewed in this paper generally promoted significant increases in wellbeing. Compared to control groups, students who participate in mindfulness interventions report increases in positive states such as optimism, positive affect, self-concept, selfacceptance, calmness, social emotional competence and general wellbeing (Kuyken et al. 2013; Broderick and Metz 2009; Schonert-Reichl and Lawlor 2010).

In Kuyken et al.'s (2013) evaluation of a secondary school mindfulness intervention, the researchers assessed the degree to which students sustained their mindfulness practice in the 3 months following completion of the intervention. Sustained mindful practice post-program was significantly positively associated with wellbeing and significantly negatively associated with stress.

Using teacher observations, Joyce et al. (2010) reported that after the mindfulness sessions students were more relaxed and settled in classes which fostered a positive classroom environment. Students also reported reductions in negative states such as depressive symptoms, stress and negative affect (Broderick and Metz 2009; Kuyken et al. 2013).

However, benefits are not apparent in every study for every outcome, and no differences were found between intervention and control groups for positive and negative emotions and depression in Mendelson et al.'s (2010) sample of primary school students. Similarly, Huppert and Johnson (2010) found no significant difference between the intervention and the control group on resiliency and general wellbeing in secondary students.

One factor that may influence whether results in mindfulness interventions are significant is the degree to which students in the intervention group practised the mindfulness skills. Degree of practice was associated with better wellbeing outcomes on two studies (Huppert and Johnson 2010; Kuyken et al. 2013).

\section{Do Mindfulness Interventions Improve School-Based and Academic Outcomes? In}

Flook et al.'s (2010) 8-week mindfulness intervention, students with poorer initial executive-cognitive function showed improvements in executive-cognitive functioning after the mindfulness training as rated by the Behavior Rating of Executive Functioning (BRIEF) scale. However, teacher and parent ratings of the children using this scale did not change between pre and post intervention. 
Summary of Attention and Awareness Interventions In summary, the two types of interventions that fall into the SEARCH pathway of attention and awareness are meditation and mindfulness. Only one third of the papers actually measured if these interventions do, in fact, improve attention and awareness. Teacher ratings of student attention and awareness did improve, but student self-reports did not coincide with the improved teacher ratings (with the exception of those students who practiced mindfulness regularly at home as a result of the intervention). Approximately, two -thirds of the studies measured the impact of meditation and mindfulness on wellbeing. The results showed that the interventions increase PA, self-acceptance and calmness as well as reducing anxiety, stress, depression and NA. When it comes to academic results, the studies, although small in number, do show a positive association between meditation and mindfulness interventions, and objective outcomes such as students' grades and subjective self-reports of cognitive functioning. These results are consistent with the recent meta-analysis on mindfulness in schools published by Maynard et al. (2017).

\subsection{Pathway Four: Relationships}

Relationships are a key supportive component of wellbeing, and a child's social skills play an important role in developing fulfilling relationships with others (Allen et al. 2017). As such, Schnitzer et al. (2007) argue that strengthening a child's ability to understand, express and manage life's social aspects are key goals of social learning. The SEARCH pathway of relationships incorporates the skills required to sustain enduring social relationships as well as capitalize on momentary social interactions (Rusk and Waters 2015). The school-based interventions included in this review that relate to the SEARCH pathway of relationships focuses on mentoring programs.

Mentoring Mentoring is a process by which a more experienced person provides a younger or less-experienced person with guidance, support and caring over an extended period of time (Karcher 2005; Kram and Ragins 2007). This paper found six schoolbased mentoring programs that fit the review criteria. Nearly all studies were conducted in the U.S. $(\mathrm{k}=5)$, while one was based in Australia. The students ranged in age from 5 to 18 years, and the total sample size across the six studies was 4160 students $(n=2835$ intervention, $n=1325$ comparison). Interventions typically took place during the school day $(\mathrm{k}=3)$, after school $(\mathrm{k}=1)$, or a combination of the two $(\mathrm{k}=2)$ and varied in duration from 8 to 12 sessions across a school year, to multiple meetings each week. Half of the studies employed RCT (Karcher 2005, 2008; Herrera et al. 2011), while the others used cohort-sequential (Ellis et al. 2009), pre-post (Fair et al. 2012) and post only designs (Dappen and Isernhagen 2006). Mentoring programs typically involved regular meetings and structured activities with teachers or older peers (e.g., senior students in the school), either one-on-one or in a group format.

Do Mentoring Programs Improve Relationships? The primary goal of mentoring interventions was typically to promote connectedness, which reflects students' "activity in and affection for the people, places and activities within their life" (Karcher 2005). Of the five studies that measured connectedness, three studies found significant effects. Results show that mentoring programs also boost a student's perceived social support 
from friends (Karcher 2008) and perceptions of the presence of a special adult in their life (Herrera et al. 2011), but did not boost feelings of social acceptance (Herrera et al. 2011) or perceived mattering (Karcher 2008).

Turning to some specific studies. Karcher (2005) found that students mentored by senior peers showed an overall increase in connectedness to school and parents, but not friends and reading. Similarly, Karcher (2008) found small, positive effects of mentoring on connectedness to peers, but not school, teachers, or culturally different peers. Following a peer support program, students reported higher opposite-sex relations self-concept scores than a control group post-intervention (maintained at 3-month follow-up) and gains in cooperative teamwork at 3-month followup, but no effects for enhanced same-sex relations self-concept (Ellis et al. 2009).

Herrera et al. (2011) found no effects on teacher or parent relationship quality among students who had participated in a Big Brothers Big Sisters mentoring program. Fair et al. (2012) also found no effects on school connectedness in either sixth grade mentors or kindergartener mentees following a year-long "Chapel Buddy" program.

In Dappen and Isernhagen's (2006) study, students reported average, or above average, scores on a mentoring scale measuring personal/social competency, caring/ respect and future aspirations (Dappen and Isernhagen 2006). Results for social skills have been mixed, with two studies finding positive effects (Karcher 2005; Dappen and Isernhagen 2006) but not a third study (Karcher 2008).

Do Mentoring Programs Improve Wellbeing Outcomes? Of the four studies that measured wellbeing outcomes of mentoring programs, two found positive effects. Karcher (2008) found small, positive effects of mentoring on global and present-oriented selfesteem. Ellis et al. (2009) found no significant effects for self-confidence, self-esteem and self-efficacy immediately post-intervention, but significant effects for selfconfidence and self-efficacy at 3-month follow-up. Karcher (2005) found no overall effect of mentoring on hope, internalising and externalising behaviours, but found that mentor attendance was positively related to gains in self-esteem. Herrera et al. (2011) found no significant effects on self-worth, or delinquency and substance use.

Do Mentoring Programs Improve School Based and Academic Outcomes? All the mentoring studies that measured school competence, a measure of school-related efficacy, found positive effects (Karcher 2005; Ellis et al. 2009; Herrera et al. 2011). Out of three studies measuring academic performance, Herrera et al. (2011) found positive effects post intervention, but not at the 15-month assessment, while the other studies found no significant effects. Herrera et al. (2011) also found no significant effects for classroom effort, and Fair et al. (2012) found no effects for school adjustment. However, Ellis et al. (2009) found positive changes on indicators of school citizenship, with students in the intervention group reporting significantly lower probully attitudes and higher honesty/trustworthiness post intervention, maintained at 3month follow-up, and an increase in pro-victim attitudes at 3-month follow-up, compared to the control group.

Summary of Relationship Interventions Taken together, there is some evidence to suggest that mentoring interventions may improve various forms of student connectedness, but these have not been consistently replicated. For example, both significant 
and null effects have been found for connectedness to school (Karcher 2005, 2008), parents (Karcher 2005; Herrera et al. 2011) and peers (Karcher 2005, 2008; Ellis et al. 2009). The evidence for self-esteem/self-concept and other wellbeing outcomes is also mixed. One strength of these studies is that they generally employed large sample sizes, with four studies involving 468 to 1490 students, while two studies were substantially smaller (Karcher 2005; Fair et al. 2012); therefore, the absence of significant effects cannot be entirely due to a lack of statistical power. However, only two studies reported follow-up results, so it is unclear whether the other significant outcomes would have long-term effects. Therefore, more evidence is required to establish the efficacy of mentoring interventions among student populations.

\subsection{Pathway Five: Coping}

Coping is defined as "constantly changing cognitive and behavioral efforts to manage specific external and/or internal demands that are appraised as taxing or exceeding the resources of the person" (Lazarus and Folkman 1984, p. 121). Coping can be problemfocused (efforts to change the situation) or emotion-focused (regulating one's emotions) (Lazarus and Folkman 1984). The SEARCH pathway of coping involves individuals being able to comprehend their situation and engage in processes to deal effectively with adversity (Rusk and Waters 2015). The school-based interventions included for the coping pathway in this review were: 1) coping interventions and 2) resilience programs.

Coping Interventions The current review paper identified eight coping intervention studies coming from Australia $(\mathrm{k}=4)$, Lithuania $(\mathrm{k}=2)$, Denmark $(\mathrm{k}=1)$, Norway $(\mathrm{k}=1)$, the U.K. $(\mathrm{k}=1)$, and the U.S. $(\mathrm{k}=1)$. Students in the studies ranged in age from six to 17 years. The total sample size across all studies was 3451 students $(n=2072$ intervention, $n=1379$ comparison). All interventions were classroom-based and ranged from eight 50-min weekly sessions to 24 weekly sessions. Interventions typically aim to expand students' repertoire of effective coping strategies and discourage nonproductive or harmful coping strategies.

Do Coping Interventions Improve Coping Skills? Six of the nine studies that assessed the impact of coping interventions directly tested whether these interventions improved coping skills. Nearly all of these studies found changes in coping strategies and problem-solving abilities. Frydenberg et al. (2004) found increases in students' tendency to turn to others for support at 6-month followup, relative to pretest levels (Study 1). However, the authors caution that results differ across gender, and may relate to the perceived authenticity of the intervention. Mishara and Ystgaard (2006) found an increase in the number and helpfulness of coping strategies in the intervention groups, relative to controls. Holen et al. (2012) found a significant increase in parent-rated (but not self-rated) active coping for intervention children and decreased oppositional coping, but no effects for emotional regulation or withdrawal coping. Other programs found students who completed a coping intervention generated significantly more problem-solving options (Schinke et al. 1987), and significant 
decreases in avoidance coping and significant increases in problem-solving and seeking social support, relative to a control groups (Collins et al. 2014).

Do Coping Interventions Improve Wellbeing Outcomes? With respect to other wellbeing outcomes, coping skills interventions were shown to increase social skills (Mishara and Ystgaard 2006), assertiveness (Schinke et al. 1987) and self-efficacy (Frydenberg et al. 2004, Study 3). The interventions were also found to decrease anxiety (Collins et al. 2014), reduce behavioural problems and reduce social problems (Mishara and Ystgaard 2006; Monkeviciene et al. 2006). However, the researchers found no significant effects on self-esteem (Schinke et al. 1987), emotional symptoms (Holen et al. 2012) peer relations (Schinke et al. 1987) and prosocial behaviour (Holen et al. 2012).

Do Coping Interventions Improve School-Based and Academic Outcomes? The impact of coping interventions on academic outcomes has received very little research attention and only one study was found that assessed academic outcomes. In the intervention undertaken by Schinke and colleagues (1987), general readiness and adaptation during the transition from elementary to junior high school was assessed using an established scale. While not a direct, objective measure of academic performance, the constructs measured in this scale are relevant to academic functioning. The results pertaining to academic functioning were not encouraging: the intervention group performed more poorly at follow up than the control group, on several indicators of academic readiness and adaption to junior high. The authors attributed these results to factors not measured in the survey battery.

Resilience Interventions Resilience can be defined as an individual's capacity for maintaining, recovering or improving mental health following life challenges (Ryff et al. 1998). To date, resilience-building interventions represent one of the most popular areas of research in student wellbeing, with 20 studies reviewed in this section. Studies come from Australia $(\mathrm{k}=10)$, U.S.A $(\mathrm{k}=6)$, U.K. $(\mathrm{k}=2)$, Canada $(\mathrm{k}=1)$, and New Zealand $(\mathrm{k}=1)$. The total sample size in these studies was 19,630 students $(9652$ intervention, 9978 comparison). While resilience interventions generally target early adolescents, these studies span a student age range of 4 to 17 . Interventions typically took place in the classroom, during regular class time $(\mathrm{k}=14)$, with others being offered as after-school programs $(\mathrm{k}=3)$ or whole-school interventions $(\mathrm{k}=2)$. The general duration and intensity of interventions was 10-12 weekly 60-90 min classroom sessions, but ranged from four $\times 40$-min units to $30 \times 45$-min sessions across 3 years (Sawyer et al. 2010). Seven studies were RCTs and the remainder used quasiexperimental designs.

Most of the interventions used cognitive-behavioural approaches which aim to prevent depression and build resilience. The Penn Resiliency Program (PRP; previously known as the Penn Prevention Program Jaycox et al. 1994) and its adaptations have been particularly influential, representing seven of the 19 studies reviewed in this section (Pattison and Lynd-Stevenson 2001; Chaplin et al. 2006; Gillham et al. 2007, 2012; Challen et al. 2014; Quayle et al. 2001; Rooney et al. 2013).

Do Resilience Interventions Increase Resilience? Although all studies aimed to build resilience, only seven studies directly assessed resilience in their battery of surveys. 
Green et al. (2007) measured cognitive hardiness (a dimension of resilience, Bonanno 2004) and found it increased in a sample of female secondary school students who undertook the intervention relative to the control group. Three of the 20 studies measured explanatory or attributional style, which might also be seen as aspect an of resilient thinking (Chaplin et al. 2006; Quayle et al. 2001; Rooney et al. 2013). None of these studies found significant effects, which is notable given that explanatory style is a key theoretical tenet of resilience interventions (Seligman et al. 1984). The remaining studies assumed resilience had increased if symptoms of mental illness were reduced at the end of resilience intervention. Yet, without a direct measure of resilience, we cannot be sure that these benefits are occurring through the mechanism of increased resilience.

Do Resilience Interventions Improve Wellbeing Outcomes? There are many aspects of wellbeing that have been studied in resilience programs, and these studies suggest a range of wellbeing gains for students including increases in self-worth (Quayle et al. 2001), social-emotional wellbeing and competence (Ashdown and Bernard 2012; Gueldner and Merrell 2011), hope (Green et al. 2007), spiritual growth (Foret et al. 2012), social skills (Ashdown and Bernard 2012), stress management skills (Foret et al. 2012), and quality relationship (Rose et al. 2009).

The most common mental health outcome to be studied in resilience programs is depression. Six studies found that resilience interventions significantly reduced depressive symptoms, compared to a control group, at some point during the post-intervention period (Challen et al. 2014; Chaplin et al. 2006; Quayle et al. 2001; Rooney et al. 2013; Shochet et al. 2001). According to a recent meta-analysis of 53 RCTs of educational and psychological depression-prevention programs for sub-clinical youth aged 6-19, the risk of developing depression was significantly reduced in time periods up to 24 months post-intervention, in a range of relevant programs (Merry et al. 2012).

In relation to other wellbeing no significant effects were found for growth mindset (Donohoe et al. 2012), self-esteem and locus of control (Foret et al. 2012), substance use and delinquent behaviours (Battistich et al. 2000), interpersonal competence, coping actions, perceived social support and peer victimisation (Battistich et al. 2000).

Do Resilience Interventions Improve School-Based and Academic Outcomes? Two resilience interventions measured academic performance. Ashdown and Bernard (2012) found a significantly greater increase in reading level in students who undertook a resilience program compared to a control sample. However, this finding should be treated as preliminary given that the subgroup was small $(n=14)$. In another study, Bernard and Walton (2011) reported that students who completed their resilience program reported their learning to be more interesting, enjoyable and inspiring. These students also reported improvements in learning confidence.

Other school related outcomes included increases in school-related life satisfaction (Rose et al. 2009), student morale and motivation (Bernard and Walton 2011), school connectedness (Battistich et al. 2000; Bernard and Walton 2011) and connectedness to peers (Bernard and Walton 2011). However, Sawyer et al. (2010) found no effect on school climate.

Summary of Intervention Results for Coping Pathway Of all the school-based interventions aligning with the SEARCH framework, it is the pathway of coping that has 
received the most peer reviewed research. Taken together the evaluations show that coping interventions do, by and large, bolster a student's coping skills but that resilience programs have no significant effect on explanatory styles (a key aspect of resilience). Coping and resilience interventions at school have been shown to increase stress management skills, hope, spiritual growth, and self-efficacy as well as reducing depression, and anxiety. Coping and resilience interventions also boost the social wellbeing of students with increases in social-emotional wellbeing, social skills, assertiveness, quality relationship and reductions in students reporting of social problems. There is some evidence that links coping and resilience programs to school-based and academic outcomes including objective outcomes like school grades and subjective outcomes like junior high readiness, adaptation to the school environment and finding learning to be more interesting, enjoyable and inspiring.

\subsection{Pathway Six: Habits and Goals}

The final pathway outlined in the SEARCH framework is habits and goals. Habits are persistent and learned patterns and preferences in decision making and behaviour (Wood and Neal 2007). With rising lifestyle related illness, understanding how to instil healthy habits is becoming increasingly important. Goals are formal milestones, endpoints, achievements or aspirations, that articulate what people desire, aim for, and are willing to invest effort into (Baumeister et al. 2006). Habits and goals are interlinked in that creating new habits can be successful steps to achieving one's goals. Goals may interact with habits and can include both the reduction of problematic or unproductive habits or behaviours (e.g. stop slouching one's shoulders) or increasing adaptive or productive behaviours or habits (e.g. paying attention to the good things in one's life). Setting goals is a key component of a well-functioning life and provides children with a sense of purpose, mastery and direction (Schunk 1990). With respect to the pathway of habits and goals, Rusk and Waters (2015) showed that psycho-social functioning is aided when individuals are able to set goals that match their values and can be used as a guide for the selection of behaviour in enduring ways that support skill acquisition. The school-based interventions that relate to this SEARCH pathway are: 1) self-regulation programs and 2) goal setting interventions.

Self-Regulation Interventions Self-regulation is an important factor in helping students set new habits and achieve their goals. The control systems relevant to self-regulation include emotional, action and motivational control, all of which serve to further one toward their goals and involve productive thinking and learning habits (Rozendaal et al. 2005). The application of self-regulation theory to an education setting is known as the field of self-regulated learning (SRL). Stoeger and Ziegler (2008) define successful SRL as a cyclical process of steps executed repeatedly, these include self-evaluation, self-monitoring and goal setting along with strategy planning, implementation and monitoring. Self-regulation is also viewed as a component of metacognition and defined as the skills and knowledge of one's own cognition and learning processes (Fuchs et al. 2003).

To assess the benefits of self-regulation interventions in schools, six studies were identified that fit the review criteria. Four studies were completed in elementary schools 
(Stoeger and Ziegler 2008; Hu et al. 2011; Fuchs et al. 2003; Wyman et al. 2010) and two at a secondary school level (de Jager et al. 2005; Rozendaal et al. 2005). The studies span a range of countries, with one in Germany (Stoeger and Ziegler 2008), China (Hu et al. 2011), two in the USA (Fuchs et al. 2003; Wyman et al. 2010) and two in the Netherlands (de Jager et al. 2005; Rozendaal et al. 2005). The combined sample size across the six studies was 1478 students ( $n=512$ intervention, $n=966$ control). Three studies were quasi experimental (de Jager et al. 2005; Fuchs et al. 2003; Stoeger and Ziegler 2008), two were true randomized experimental designs (Hu et al. 2011; Wyman et al. 2010) and one study was a quantitative observational design (Rozendaal et al. 2005). All studies involve self-regulation interventions that take place in the classroom lasting between 5 weeks and 4 years. Age range of the students was preschool to 17 years.

Do Self-Regulation Interventions Improve Self-Regulation? Four of the six studies reviewed in this paper directly measured if self-regulation, or the closely conceptualized construct of meta-cognition, improved after school-based self-regulation interventions. The overall results show that when students are put through interventions that teach them how to understand and regulate their thinking and learning patterns, they report benefits in regulation, thinking ability and higher metacognition (Hu et al. 2011; de Jager et al. 2005). For example, Fuchs et al. (2003), found that students performed better on self-regulated learning questions relating to self-efficacy, goal orientation, self-monitoring and effort when they were a part of the self-regulated intervention. Rozendaal et al., (2005) also observed that greater teacher adherence to self-regulated learning intervention was related to greater increases in deep-level processing in students.

Do Self-Regulation Interventions Improve Student Wellbeing? Self-regulation interventions have been shown to improve various wellbeing outcomes such as self-efficacy, motivation and positive social environments (Rozendaal et al. 2005; Stoeger and Ziegler 2008). Stoeger and Ziegler (2008) found greater student self-efficacy and lowered helplessness after undertaking a selfregulation intervention. Wyman et al. (2010) also found fewer behavioral problems (e.g., aggression and shyness) for students participating in an intervention that aimed to build emotional self-regulation. Peer social skills also improved for girls but there was no significant change for boys (Wyman et al. 2010).

\section{Do Self-Regulation Interventions Improve School-Based and Academic} Outcomes? Only two of the six studies looked at the school-based and academic outcomes of running self-regulation outcomes. Research by $\mathrm{Hu}$ et al. (2011) as well as Stoeger and Ziegler (2008) found that learning and thinking about self-regulation interventions gave rise to a more positive approach to obtaining knowledge, a more positive atmosphere for encouraging group discussion, less fear in learning and more bravery to express one's ideas. Stoeger and Ziegler (2008) also found that students who completed self-regulation intervention groups reported better school performance. The study by $\mathrm{Hu}$ et al. (2011) found that students who were in the self-regulation program showed increases in academic performance. Interestingly, these academic benefits were most rapid in the 3rd grade students compared to 1 st and 2nd grade students suggesting that there is a developmental aspect to gaining benefits from self-regulated learning. 
Goal-Based Interventions Seven goal-based interventions were located for the current analysis: two were conducted in elementary schools and five in secondary schools. The interventions were conducted in the UK $(\mathrm{k}=2)$ (Humphrey et al. 2010; Weigand and Burton 2002), the US $(k=2)$ (Duckworth et al. 2011; Duckworth et al. 2013) Greece $(\mathrm{k}=1)$ (Barkoukis et al. 2008), Canada $(\mathrm{k}=1)$ (Senécal et al. 2008) and Finland $(\mathrm{k}=1)$ (Jaakkola and Liukkonen 2006). The total sample size across the studies is $N=1186$. The age range of participants was 6 to 16 years. Four of these intervention studies utilize a sport or physical education setting and three were in regular class setting (Barkoukis et al. 2008; Jaakkola and Liukkonen 2006; Senécal et al. 2008; Weigand and Burton 2002) and one study is classroom based (Humphrey et al. 2010). Two of the studies were RCT and the other five were quasi experimental. Interventions ranged between one lesson through to a one year program.

Do goal-based interventions improve goal setting? Results from the goal-based interventions found direct benefits for the interventions on outcomes such as goal orientation (Barkoukis et al. 2008; Jaakkola and Liukkonen 2006; Weigand and Burton 2002), goal motivation (Barkoukis et al. 2008; Jaakkola and Liukkonen 2006; Weigand and Burton 2002), and task orientation (Barkoukis et al. 2008; Weigand and Burton 2002).

Do goal-based interventions improve wellbeing outcomes Improvements in various aspects of student wellbeing have also been observed in goal-based interventions including staff ratings of social and emotional wellbeing (Humphrey et al. 2010) as well as students' ratings of higher perceived competence (Weigand and Burton 2002), greater satisfaction (Weigand and Burton 2002), and self-determined motivation (Jaakkola and Liukkonen 2006).

In addition to the impact on positive aspects of wellbeing, goal setting interventions in schools also have the potential to reduce the presence of negative states. Reductions in behavioral problems and emotional difficulties in children identified as in need of extra support were observed following the "Going for Goals" intervention (Humphrey et al., 2013). In addition, lower anxiety (Barkoukis et al. 2008), less boredom (Weigand and Burton 2002) and reductions in amotivation (Jaakkola and Liukkonen 2006) were found following the TARGET framework goal interventions.

Do goal-based interventions improve school-based and academic outcomes A number of school related outcomes have been assessed following goal-based interventions. For example, Barkoukis et al. (2008) reported higher enjoyment in physical education classes and class motivation following a goal setting intervention. Other outcomes include higher perceived academic competence (Weigand and Burton 2002) and greater class satisfaction (Weigand and Burton 2002). Finally, in a goal setting intervention in female school basketball school teams, Senécal et al. (2008) found improvements in student reports of the school team environment and school team cohesion for the student teams who went through the goal setting intervention compared to the control condition.

Summary of Intervention Results for Coping Pathway Taken together, results of the 13 school-based interventions related to habits and goals suggest these programs may support students in setting better learning habits and goals, through enhancing their understanding of how to regulate their thinking and learning patterns and through 
fostering goal related behaviours such as goal orientation, goal motivation and task orientation. These programs are also significantly related to a host of wellbeing outcomes including higher self-efficacy, motivation and social-emotional wellbeing, as well as lower helplessness, fewer emotional difficulties, reduced anxiety and less boredom. Social outcomes of these programs also included perceptions of more positive social environments, better social skills with peers (for girls but not boys) and fewer behavioral problems (e.g., aggression and shyness). A number of school-based and academic outcomes were also found with these interventions including increased academic performance, greater class satisfaction and class motivation. Future research can also explore the finding that self-regulation programs need to be tailored to developmental levels.

\section{Discussion}

The SEARCH framework has been developed as a tool to support future research and practice in positive education and to help overcome some of the challenges the field is currently facing due to its rapid growth and expansion including an over-relying on the findings of individual studies and interventions, a fragmented approach that fails to capitalize on interconnections across positive education interventions and a failure to see the big picture and use this to cumulatively build student wellbeing over time. SEARCH is a data-driven, multidimensional and actionable framework, comprising six evidence-based pathways to foster wellbeing. The higher-order nature of these pathways provides a comprehensive and integrated focus whilst still allowing the flexibility needed for researchers to explore finer-grained research questions and required for teachers to tailor specific interventions based on contexts and needs.

To further establish the utility of SEARCH for school students the current review paper examined whether the existing evidence from published positive education interventions mapped on to the six pathways. Eighty-five ${ }^{6}$ peer-reviewed intervention studies were identified that had tested the effects of each of the SEARCH pathways on students. The interventions were tested in school students ranging from ages 4-18, with studies split roughly into thirds across primary/junior/elementary schools (31.5\%), middle schools (34\%) and senior schools (30\%). The interventions came from 14 different countries across the world and had a combined student population of 35,888 .

The intervention studies showed a consistent pattern of evidence that each of the six pathways can be effectively targeted to improve wellbeing and academic outcomes, although tests of efficacy were not universally significant. Positive education interventions mapping on to SEARCH were found to increase optimism, hope, life satisfaction, motivation, self-confidence, positive affect, engagement and social wellbeing, to name a few. Interventions were also found to reduce various aspects of student ill-being such

\footnotetext{
${ }^{6}$ It is noteworthy that there is a much greater number of published peer reviewed studies that support the SEARCH pathways than were not included in the current paper. The search protocol identified many other types of studies that mapped on the six SEARCH elements (e.g. cross- sectional studies, longitudinal studies, qualitative papers and case studies), however these papers were excluded on the basis of the strict inclusion criteria outlined in the method. If one were to expand the reach of the literature review beyond intervention studies further support for the validity an applicability of the six SEARCH pathways in schools would be found.
} 
as stress, negative affect, anxiety and depression. In line with Seligman et al.'s (2009) dual definition of positive education as an approach to enhance wellbeing and academic achievement, there was evidence in this review that interventions which foster SEARCH pathways bolsteri academic grades and other school-related outcomes such as student satisfaction, academic expectations, academic motivation, and perceptions of academic ability.

\subsection{Using SEARCH as a Meta-Framework to Guide Future Research}

We offer SEARCH as a useful framework to help researchers scaffold and build the science of positive education. For example, when researchers are designing and/or evaluating specific interventions, the meta-framework can help in conceptualising a multi-faceted model of wellbeing as well as assisting them to see how the variables of the study are situated against the array of other topics. A positive consequence of this is that it may create greater connections amongst researchers and foster stronger cross-pollination across topics when pulled together by an overarching framework like SEARCH. For example, when researchers working on emotional intelligence or gratitude interventions can see that they both are working towards the same high-order pathway construct of emotional management, they may be more likely to also connect and integrate their interventions which are currently being studied separately.

In addition to the within pathway inter-connectedness, we hope that SEARCH will also prompt researchers to more clearly see the interconnections across the pathways and motivate the study of integrated, coherent and testable models of wellbeing. For example, researchers may test if building up a student's attention and awareness, in the form of mindful practices, also helps that student to build their coping ability during stressful times by showing students how to detect their distress/poor coping signals earlier (due having learnt how to pay attention to their negative thoughts and feelings). In this case, the researchers test how the two pathways of SEARCH - the pathway of attention and awareness and the pathway of coping - support one another and lead to synergistic gains.

One potential avenue of research using SEARCH may be in developmental psychology where the framework can be used to create an age-stage appropriate scope and sequencing of wellbeing curriculums. In addition, research may also show that certain pathways are needed to be developed earlier than other pathways in certain ages. Perhaps there is a maturity effect where the competencies in one pathway are needed for another pathway to fully develop to come to fruition. As a speculation, it could be that attention/awareness and emotional management are pathways that schools need to target in the early years to allow for the full development of coping and resilience in the teen years? Such developmental questions on how to best build wellbeing over time can be scaffolded by using the SEARCH metaframework.

\subsection{Gaps in Positive Education Research}

The current review of existing positive education literature has identified a number of gaps that can be addressed through future research. First, despite Seligman et al.'s (2009) dual definition of positive education as an approach that teaches both for wellbeing and 
academic learning, only one sixth of positive education studies included school-related or academic outcomes. Given the symbiosis between wellbeing and learning (see Waters 2017, for a review of the research linking wellbeing and academic performance) and the priority on academic outcomes that school leaders and administers must place when allocating resources (White and Kern 2018), it is crucial for positive education researchers to more frequently incorporate academic outcomes and other school-related outcomes in their measures.

Second, while the bulk of intervention studies include wellbeing outcomes, only one third, on average, addressed whether the focus of the intervention itself actually fostered the construct it was targeting: the proposed mechanism or process variable through which beneficial outcomes are conveyed. For example, $65 \%$ of the resilience interventions did not explicitly test student resilience. Instead, in the absence of a measure of resilience, researchers assumed that if depression and anxiety reduced, this was attributable to resilience skills improving. Likewise, in the meditation interventions, only $16 \%$ of the studies directly tested if meditative attention improved. Again, the assumption was made that because wellbeing improved (i.e., students reported being calmer and less stressed at the end of the intervention), this was because they had learnt the skills of meditation. While it is a reasonable assumption that resilience and attention have gone up as a result of these schoolbased interventions, it could also be that other factors about the program are leading to the outcomes such as teacher-student relationship, time to spend on non-academic tasks, bonding with classmates around personal topics, or enjoying the material. Given that positive education interventions intend to cultivate the psycho-social skills that students can continue to build and apply to enhance their own wellbeing in an ongoing way, it is important for future researchers to directly test the active ingredient of the of the intervention (e.g. resilience, meditation). These are sometimes referred to as manipulation checks and are critical to ensure programs are effective.

Third, cross-cultural research on positive education interventions were largely absent in this review with only 2 of the 75 studies conducted in collectivistic countries. This result could well be shaped by the data base used in the systematic literature review. The current paper used Scopus ${ }^{\circledR}$, Google Scholar, PsycINFO®, and Web of Science®. Perhaps studies from eastern and developing countries are not published in these main libraries. It could also be that the parameters of the current paper, which looked only at the six SEARCH pathways, limited the inclusion of studies from Eastern countries and developing countries. Perhaps cross-cultural researchers are looking at topics that fall outside of the higher-order pathways of strengths, emotional management, attention and awareness, relationships, coping and habits and goals. However, given that the six pathways are broad in nature and were comprehensively derived from a large-scale analysis of the field of positive psychology (including a range of topics and practises from over 18,000 articles), the lack of cultural diversity is concerning and points researchers to the need for future research on crosscultural applications in positive education interventions.

Another gap identified in this review paper is the disparity of research conducted between the six pathways in positive education interventions. In this review, coping was the pathway which had the highest number of studies $(n=29)$. Habits and goals $(n=13)$ and attention and awareness $(n=13)$ had an equal number of intervention studies followed by strengths $(n=7)$ and relationships $(n=6)$. It may be that future researchers focus more on schoolbased interventions which build up the pathways that had fewer studies. However, it must be remembered that we chose to review interventions that had a specific focus on each pathway. 
Dual or multi-dimensional programs such as social-emotional (SEL) programs were not included. This decision was made so that we could establish if each separate SEARCH pathway has evidence of effectiveness in its own right, rather than because it is bundled with other wellbeing components. Had we included multi-component interventions the number of studies for the relationships pathway and emotional management pathway would have been considerably larger due to the existing literature based on SEL programs.

Finally, this review points towards the need for more RCT designs to be used when testing the effectiveness of positive education interventions. In terms of the study design, $29 \%$ were RCT, $65 \%$ were quasi-experimental and $4 \%$ were other (e.g. within sample, repeated-measures design, cohort sequential designs). Again, it must be recognised that we had strict inclusion criteria and the percentages above would differ with less conservative criteria. That said, even if with the strict criteria drawing on only the higher quality designs, more than two thirds of the studies are not using what can be considered the 'gold standard' in establishing efficacy.

One untapped area for future research is the effect of context and where and how the interventions are delivered. In the current review, the bulk of the interventions were run in the classroom (83\%), followed by after-school programs (10\%), school sports teams (4\%), whole-school initiatives (2\%) and other (1\%). There is some evidence already to suggest that interventions have the greatest impact on students when they are delivered by teachers (Waters et al. 2015; Chodkiewicz and Boyle 2017) but this may also depend on the particular nature of the intervention. Perhaps interventions that tap the pathways of coping and relationships have a greater effectiveness in the classroom due to the stronger bond with one's teacher but it could be that strengths interventions and goal interventions do equally well in other context such as sport teams, after school programs, student buddy programs and peer coaching.

\subsection{Using SEARCH as a Meta-Framework to Guide School Practice}

SEARCH is not only an evidence-based framework to guide research in the field, it is also a framework that can guide practical application in schools, something that White and Kern (2018) highlight as being of central importance. We offer SEARCH as a framework to assist schools when implementing positive education interventions in a co-ordinated manner across different year levels and across all areas of the school: in class, on the sports field, in orchestra, performing arts, chess club, computer club, other co-curricula activities, in the school yard, the school corridors and discipline situations and so on.

SEARCH provides a data-driven, action-research informed framework for teachers to use when designing positive education interventions. Educators are encouraged to think not only about the content of the intervention but how that intervention can be used to build one or more of the higher-order pathways of wellbeing. For example, while the content of the intervention might be gratitude, the SEARCH framework would help teachers design the gratitude intervention in ways that ensure it improves a student's broader emotional management. Additionally, given Rusk et al. (2017) Synergistic Change Model (SCM) which suggests that interventions are most effective when they are designed in ways that create inter-connections across the pathways, teachers can use SEARCH to design schoolbased interventions that focus on multiple pathways. For example, when designing a gratitude intervention for students, teachers can be aware of how to design the intervention in a way that creates the ongoing habit of gratitude (rather than a one-off exercise) thus 
also supporting the habits and goals pathways. The can also think about how gratitude interventions can be used to influence the student's emotions (emotional management), that can be then used train them how to change their focus away from problems and towards what is going well for them (attention and awareness), in a way that encourages them to be thankful towards others (social relationships). In this way the intervention itself is a vehicle that allows the pathways to mutually reinforce one another. This approach moves the field away from an approach that focuses on interventions to look deeper at what pathways are being built up over time.

Beyond the design of individual positive education interventions, SEARCH can be used to design larger wellbeing curriculums. Such curriculums can teach students how to play to their strengths, manage their emotions, focus their attention, build supportive relationships, cope with adversity and set health habits and goals. SEARCH can also be used by school leaders to audit and evaluate the degree to which existing wellbeing programs tap into one or more of the six higher-order pathways.

Positive education should not only be about student wellbeing, it should also include whole-school approaches that build faculty and staff wellbeing (Waters 2011; White and Murray 2015). The fact that only $2 \%$ of positive education programs reviewed in this study were whole-school offers food for thought for school leaders. Staff and faculty can be offered professional development that helps them build their own levels of SEARCH, thus making positive education truly whole-school. School leaders and administrators can find strategic and consistent ways to infuse SEARCH into elements of the school that impact faculty and staff such as recruitment and selection, performance development, professional learning, employee wellbeing programs and staff/faculty room culture. A key question for school leaders prompted by the SEARCH framework is 'How can I intentionally create a culture that fosters strengths, emotional management, attention and awareness, relationships, coping and habits and goals for all the adult members of the school?'

\section{Conclusion}

In 2009, Seligman et al. suggested "positive education will form the basis of a new prosperity" (p. 293). Since that time, the field has grown in promising ways. A decade on and Seligman (2018b) states that "much of the fulcrum of positive psychology will rest on the fulcrum of positive education" (p. 294).

It is certainly an exciting time for the field with the rapid expansion of science and practice. However, this growth has put positive education at risk of lacking a cohesive direction and of failing to build the cumulative evidence needed to advance the field. As White and Colleagues argue, this can lead to ineffective, or even harmful, outcomes for students (White and Murray 2015; White 2016; White and Kern 2018).

In this paper we have argued that a meta-framework can prevent these risks by providing higher-order parameters that help us to guide future research and practise in ways that ensure more consistent, integrated, cohesive and perhaps even synergistic outcomes. The SEARCH framework, developed from a large-scale bibliometric analysis of the field combined with action research has been supported through a systematic review of evidence in the current paper which has shown that schools can build up each of the six pathways through interventions in and out of the classroom. 
We offer this framework to our colleagues in the field and hope it is used far and wide to build rigorous research and reliable practices that help positive education to achieve the dual purpose put forward by Seligman et al. (2009) of boosting wellbeing and academic outcomes.

Acknowledgement The authors thank and acknowledge three dedicated research assistants, Ms. Jessie Sun, Ms. Alice A and Ms. Alice C, for their contributions to this paper, specifically in locating articles and assisting in preparation of drafting the manuscript.

\section{Compliance with Ethical Standards}

Conflict of Interest On behalf of all authors, the corresponding author states that there is no conflict of interest.

Open Access This article is distributed under the terms of the Creative Commons Attribution 4.0 International License (http://creativecommons.org/licenses/by/4.0/), which permits unrestricted use, distribution, and reproduction in any medium, provided you give appropriate credit to the original author(s) and the source, provide a link to the Creative Commons license, and indicate if changes were made.

\section{References}

Allen, K. A., Kern, M. L., Vella-Brodrick, D., \& Waters, L. (2017). School Values: A Comparison of Academic Motivation, Mental Health Promotion, and School Belonging With Student Achievement. The Educational and Developmental Psychologist, 1-17.

Anticich, S. A. J., Barrett, P. M., Silverman, W., Lacherez, P., \& Gillies, R. (2013). The Prevention of childhood anxiety and promotion of resilience among preschool-aged children: A universal school based trial. Advances in School mental Health Promotion, 6, 93-121. https://doi.org/10.1080/1754730x.2013.784616.

Ashdown, D. M., \& Bernard, M. E. (2012). Can explicit instruction in social and emotional learning skills benefit the social-emotional development, wellbeing, and academic achievement of young children? Early Childhood Education Journal, 39(6), 397-405.

Austin, D. B. (2005). The effects of a strengths development intervention program upon the self perception of students' academic abilities (Doctoral dissertation, [Sl: sn]).

Barkoukis, V., Tsorbatzoudis, H., \& Grouios, G. (2008). Manipulation of motivational climate in physical education: Effects of a seven-month intervention. European Physical Education Review, 14(3), 367-387.

Battistich, V., Schaps, E., Watson, M., Solomon, D., \& Lewis, C. (2000). Effects of the Child Development Project on students' drug use and other problem behaviors. The Journal of Primary Prevention, 21(1), 75-99.

Baumeister, R. F., Gailliot, M., DeWall, C. N., \& Oaten, M. (2006). Self-regulation and personality: How interventions increase regulatory success, and how depletion moderates the effects of traits on behavior. Journal of Personality, 74(6), 1773-1802.

Beauchemin, J., Hutchins, T. L., \& Patterson, F. (2008). Mindfulness meditation may lessen anxiety, promote social skills, and improve academic performance among adolescents with learning disabilities. Complementary Health Practice Review, 13(1), 34-45.

Benninga, J. S., Berkowitz, M. W., Kuehn, P., \& Smith, K. (2006). Character and academics: What good schools do. Phi Delta Kappan, 87(6), 448-452.

Bernard, M. E., \& Walton, K. (2011). The effect of You Can Do It! Education in six schools on student perceptions of wellbeing, teaching-learning and relationships. The Journal of Student Wellbeing, 5(1), 22-37.

Black, D. S., Milam, J., \& Sussman, S. (2009). Sitting-meditation interventions among youth: A review of treatment efficacy. Pediatrics, 124(3), e532-e541.

Bonanno, G. A. (2004). Loss, trauma, and human resilience: have we underestimated the human capacity to thrive after extremely aversive events? American psychologist, 59(1), 20.

Brackett, M. A., Rivers, S. E., Reyes, M. R., \& Salovey, P. (2012). Enhancing academic performance and social and emotional competence with the RULER feeling words curriculum. Learning and Individual Differences, 22(2), 218-224. 
Brdar, I., \& Kashdan, T. B. (2010). Character strengths and wellbeing in Croatia: An empirical investigation of structure and correlates. Journal of research in personality, 44(1), 151-154.

Broderick, P. C., \& Metz, S. (2009). Learning to BREATHE: A pilot trial of a mindfulness curriculum for adolescents. Advances in school mental health promotion, 2(1), 35-46.

Brunwasser, S. M., Gillham, J. E., \& Kim, E. S. (2009). A meta-analytic review of the Penn Resiliency Program's effect on depressive symptoms. Journal of consulting and clinical psychology, 77(6), 1042.

CASEL (2017). http://www.casel.org/about2-/ (retrieved 2017-04-01).

Castillo, R., Salguero, J. M., Fernández-Berrocal, P., \& Balluerka, N. (2013). Effects of an emotional intelligence intervention on aggression and empathy among adolescents. Journal of Adolescence, 36(5), 883-892.

Challen, A. R., Machin, S. J., \& Gillham, J. E. (2014). The UK Resilience Programme: A school-based universal nonrandomized pragmatic controlled trial. Journal of Consulting and Clinical Psychology, $82(1), 75$.

Chaplin, T. M., Gillham, J. E., Reivich, K., Elkon, A. G., Samuels, B., Freres, D. R., et al. (2006). Depression prevention for early adolescent girls: A pilot study of all girls versus co-ed groups. The Journal of early adolescence, 26(1), 110-126.

Chodkiewicz, A. R., \& Boyle, C. (2017). Positive psychology school-based interventions: A reflection on current success and future directions. Review of Education, 5(1), 60-86.

Collins, S., Woolfson, L. M., \& Durkin, K. (2014). Effects on coping skills and anxiety of a universal school-based mental health intervention delivered in Scottish primary schools. School Psychology International, 35(1), 85-100.

Dappen, L., \& Isernhagen, J. C. (2006). Urban and nonurban schools: Examination of a statewide student mentoring program. Urban Education, 41(2), 151-168.

Dawood, R. (2013). Positive psychology in school-based psychological intervention: A study of the evidencebase. The European Journal of Social \& Behavioural Sciences, 5(2), 954.

Diener, E., Suh, E. M., Lucas, R. E., \& Smith, H. L. (1999). Subjective wellbeing: Three decades of progress. Psychological bulletin, 125(2), 276.

Donaldson, S. I., Dollwet, M., \& Rao, M. A. (2015). Happiness, excellence, and optimal human functioning revisited: Examining the peer-reviewed literature linked to positive psychology. The Journal of Positive Psychology, 10(3), 185-195.

Donohoe, C., Topping, K., \& Hannah, E. (2012). The impact of an online intervention (Brainology) on the mindset and resiliency of secondary school pupils: a preliminary mixed methods study. Educational Psychology, 32(5), 641-655.

Duckworth, A. L., Grant, H., Loew, B., Oettingen, G., \& Gollwitzer, P. M. (2011). Self-regulation strategies improve self-discipline in adolescents: Benefits of mental contrasting and implementation intentions. Educational Psychology, 31(1), 17-26.

Duckworth, A. L., Kirby, T. A., Gollwitzer, A., \& Oettingen, G. (2013). From fantasy to action: Mental contrasting with implementation intentions (MCII) improves academic performance in children. Social Psychological and Personality Science, 4(6), 745-753.

Durlak, J. A., Weissberg, R. P., Dymnicki, A. B., Taylor, R. D., \& Schellinger, K. B. (2011). The impact of enhancing students' social and emotional learning: A meta-analysis of school-based universal interventions. Child Development, 82(1), 405-432.

Ellis, L. A., Marsh, H. W., \& Craven, R. G. (2009). Addressing the Challenges Faced by Early Adolescents: A Mixed-Method Evaluation of the Benefits of Peer Support. American journal of community psychology, 44(1-2), 54-75.

Fair, C. D., Hopkins, K., \& Decker, A. (2012). Developmental mentoring, relationship quality and school adjustment: the Chapel Buddy programme. Early Child Development and Care, 182(1), 107-121.

Flook, L., Smalley, S. L., Kitil, M. J., Galla, B. M., Kaiser-Greenland, S., Locke, J., et al. (2010). Effects of mindful awareness practices on executive functions in elementary school children. Journal of Applied School Psychology, 26(1), 70-95.

Foret, M. M., Scult, M., Wilcher, M., Chudnofsky, R., Malloy, L., Hasheminejad, N., \& Park, E. R. (2012). Integrating a relaxation response-based curriculum into a public high school in Massachusetts. Journal of adolescence, 35(2), 325-332.

Forgeard, M. J., Jayawickreme, E., Kern, M. L., \& Seligman, M. E. (2011). Doing the right thing: Measuring wellbeing for public policy. International Journal of Wellbeing, 1(1).

Fredrickson, B. L., \& Branigan, C. A. (2001). Positive emotions. In T. J. Mayne \& G. A. Bonnano (Eds.), Emotion: Current issues and future directions (pp. 123-151). New York: Guilford Press.

Froh, J. J., Sefick, W. J., \& Emmons, R. A. (2008). Counting blessings in early adolescents: An experimental study of gratitude and subjective wellbeing. Journal of school psychology, 46(2), 213-233. 
Froh, J. J., Yurkewicz, C., \& Kashdan, T. B. (2009). Gratitude and subjective wellbeing in early adolescence: Examining gender differences. Journal of adolescence, 32(3), 633-650.

Froh, J. J., Huebner, E. S., Youssef, A. J., \& Conte, V. (2011). Acknowledging and appreciating the full spectrum of the human condition: School Psychology's (limited) focus on positive psychological functioning. Psychology in the Schools, 48(2), 110-123.

Froh, J. J., Bono, G., Fan, J., Emmons, R. A., Henderson, K., Harris, C., et al. (2014). Nice thinking! An educational intervention that teaches children to think gratefully. School Psychology Review, 43(2), 132.

Frydenberg, E., Lewis, R., Bugalski, K., Cotta, A., McCarthy, C., Luscombe-smith, N., \& Poole, C. (2004). Prevention is better than cure: Coping skills training for adolescents at school. Educational Psychology in Practice, 20(2), 117-134.

Fuchs, L. S., Fuchs, D., Prentice, K., Burch, M., Hamlett, C. L., Owen, R., \& Schroeter, K. (2003). Enhancing third-grade student'mathematical problem solving with self-regulated learning strategies. Journal of educational psychology, 95(2), 306.

Gillham, J. E., Reivich, K. J., Freres, D. R., Chaplin, T. M., Shatté, A. J., Samuels, B., et al. (2007). Schoolbased prevention of depressive symptoms: A randomized controlled study of the effectiveness and specificity of the Penn Resiliency Program. Journal of consulting and clinical psychology, 75(1), 9.

Gillham, J. E., Reivich, K. J., Brunwasser, S. M., Freres, D. R., Chajon, N. D., Kash-MacDonald, V. M., et al. (2012). Evaluation of a group cognitive-behavioral depression prevention program for young adolescents: A randomized effectiveness trial. Journal of Clinical Child \& Adolescent Psychology, 41(5), 621-639.

Green, S., Grant, A., \& Rynsaardt, J. (2007). Evidence-based life coaching for senior high school students: Building hardiness and hope. International Coaching Psychology Review, 2(1), 24-32.

Gueldner, B., \& Merrell, K. (2011). Evaluation of a social-emotional learning program in conjunction with the exploratory application of performance feedback incorporating motivational interviewing techniques. Journal of Educational and Psychological Consultation, 21(1), 1-27.

Hagelskamp, C., Brackett, M. A., Rivers, S. E., \& Salovey, P. (2013). Improving classroom quality with the ruler approach to social and emotional learning: Proximal and distal outcomes. American Journal of Community Psychology, 51(3-4), 530-543.

Herrera, C., Grossman, J. B., Kauh, T. J., \& McMaken, J. (2011). Mentoring in schools: An impact study of Big Brothers Big Sisters school-based mentoring. Child development, 82(1), 346-361.

Hildreth, G. H. (1930). Psychological service for school problems. Yonkers-on-Hudson: World Book.

Holen, S., Waaktaar, T., Lervåg, A., \& Ystgaard, M. (2012). The effectiveness of a universal school-based programme on coping and mental health: A randomised, controlled study of Zippy's Friends. Educational Psychology, 32(5), 657-677.

Hu, W., Adey, P., Jia, X., Liu, J., Zhang, L., Li, J., \& Dong, X. (2011). Effects of a 'Learn to Think'intervention programme on primary school students. British Journal of Educational Psychology, 81(4), 531-557.

Humphrey, N., Kalambouka, A., Wigelsworth, M., \& Lendrum, A. (2010). Going for goals: An evaluation of a short, social-emotional intervention for primary school children. School Psychology International, $31(3), 250-270$.

Huppert, F. A., \& Johnson, D. M. (2010). A controlled trial of mindfulness training in schools: The importance of practice for an impact on wellbeing. The Journal of Positive Psychology, 5(4), 264-274.

Immordino-Yang, M. H., \& Damasio, A. (2007). We feel, therefore we learn: The relevance of affective and social neuroscience to education. Mind, brain, and education, 1(1), 3-10.

Jaakkola, T., \& Liukkonen, J. (2006). Changes in students' self-determined motivation and goal orientation as a result of motivational climate intervention within high school physical education classes. International Journal of Sport and Exercise Psychology, 4(3), 302-324.

de Jager, B., Jansen, M., \& Reezigt, G. (2005). The development of metacognition in primary school learning environments. School effectiveness and school improvement, 16(2), 179-196.

Jaycox, L. H., Reivich, K. J., Gillham, J., \& Seligman, M. E. (1994). Prevention of depressive symptoms in school children. Behaviour research and therapy, 32(8), 801-816.

Jensen, E. (2008). Brain-based learning: The new paradigm of teaching. Thousand Oaks: Corwin Press.

Joyce, A., Etty-Leal, J., Zazryn, T., \& Hamilton, A. (2010). Exploring a mindfulness meditation program on the mental health of upper primary children: A pilot study. Advances in School Mental Health Promotion, $3(2), 17-25$.

Kabat-Zinn, J. (2003). Mindfulness-based interventions in context: past, present, and future. Clinical Psychology: Science and Practice, 10(2), 144-156.

Kabat-Zinn, J., \& Santorelli, S. (1999). Mindfulness-based stress reduction professional training resource manual. Worchester: Center for Mindfulness in Medicine, Health Care and Society. 
Karcher, M. J. (2005). The effects of developmental mentoring and high school mentors' attendance on their younger mentees' self-esteem, social skills, and connectedness. Psychology in the Schools, 42(1), 65-77.

Karcher, M. (2008). The cross-age mentoring program: A developmental intervention for promoting students' connectedness across grade levels. Professional School Counseling, 12(2), 137-143.

Kern, M. L., Adler, A., Waters, L. E., \& White, M. A. (2015). Measuring whole-school wellbeing in students and staff. In Evidence-based approaches in positive education (pp. 65-91). Springer Netherlands.

Keyes, C. L., \& Annas, J. (2009). Feeling good and functioning well: Distinctive concepts in ancient philosophy and contemporary science. The Journal of Positive Psychology, 4(3), 197-201.

Kram, K. E., \& Ragins, B. (2007). The Landscape of Mentoring in the twenty-first Century. In K. E. Kram \& B. R. Ragins (Eds.), Handbook of mentoring at work theory, research, and practice. Thousand Oaks: Sage Publications.

Kuyken, W., Weare, K., Ukoumunne, O. C., Vicary, R., Motton, N., Burnett, R., et al. (2013). Effectiveness of the Mindfulness in Schools Programme: non-randomised controlled feasibility study. The British Journal of Psychiatry, 203(2), 126-131.

Lazarus, R. S., \& Folkman, S. (1984). Coping and adaptation. The handbook of behavioral medicine, 282-325.

Lyubomirsky, S., King, L., \& Diener, E. (2005). The benefits of frequent positive affect: Does happiness lead to success? Psychological Bulletin, 131(6), 803-855.

Madden, W., Green, S., \& Grant, A. M. (2011). A pilot study evaluating strengths-based coaching for primary school students: Enhancing engagement and hope. International Coaching Psychology Review, 6(1), 71-83.

Marques, S. C., Lopez, S. J., \& Pais-Ribeiro, J. L. (2011). "Building hope for the future": A program to foster strengths in middle-school students. Journal of Happiness Studies, 12(1), 139-152.

Maynard, B., Solis, M., Miller, V., \& Brendel, K. (2017). Mindfulness-based interventions for improving cognition, academic achievement, behavior and socio-emotional functioning of primary and secondary students. Campbell Collaboration, 2017(13). https://campbellcollaboration.org/library/mindfulnessbased-interventions-primary-and-secondary-school-students.html.

Mendelson, T., Greenberg, M. T., Dariotis, J. K., Gould, L. F., Rhoades, B. L., \& Leaf, P. J. (2010). Feasibility and preliminary outcomes of a school-based mindfulness intervention for urban youth. Journal of abnormal child psychology, 38(7), 985-994.

Merry, S. N., Hetrick, S. E., Cox, G. R., Brudevold-Iversen, T., Bir, J. J., \& McDowell, H. (2012). Cochrane Review: Psychological and educational interventions for preventing depression in children and adolescents. Evidence-Based Child Health: A Cochrane Review Journal, 7(5), 1409-1685.

Mishara, B. L., \& Ystgaard, M. (2006). Effectiveness of a mental health promotion program to improve coping skills in young children: Zippy's Friends. Early Childhood Research Quarterly, 21(1), 110-123.

Monkeviciene, O., Mishara, B. L., \& Dufour, S. (2006). Effects of the Zippy's Friends programme on children's coping abilities during the transition from kindergarten to elementary school. Early Childhood Education Journal, 34(1), 53-60.

Napoli, M., Krech, P. R., \& Holley, L. C. (2005). Mindfulness training for elementary school students: The attention academy. Journal of Applied School Psychology, 21(1), 99-125.

Nathanson, L., Rivers, S. E., Flynn, L. M., \& Brackett, M. A. (2016). Creating emotionally intelligent schools with RULER. Emotion Review, 8(4), 1-6.

Nidich, S. I., \& Nidich, R. J. (1989). Increased academic achievement at Maharishi School of the Age of Enlightenment: A replication study. Education, 109(3), 302-304.

Nidich, S., Mjasiri, S., Nidich, R., Rainforth, M., Grant, J., Valosek, L., et al. (2011). Academic achievement and transcendental meditation: A study with at-risk urban middle school students. Education, 131(3), 556-565.

Norrish, J. M. (2015). Positive education: the geelong grammar school journey. Oxford Positive Psychology Series.

Pattison, C., \& Lynd-Stevenson, R. M. (2001). The prevention of depressive symptoms in children: The immediate and long-term outcomes of a school based program. Behaviour Change, 18, 92-102.

Pekrun, R., Goetz, T., Titz, W., \& Perry, R. P. (2002). Academic emotions in students' self-regulated learning and achievement: A program of qualitative and quantitative research. Educational Psychologist, 37(2), 91-105.

Peterson, C. (2006). A primer in positive psychology. London: Oxford University Press.

Peterson, C., \& Seligman, M. E. (2004). Character strengths and virtues: A handbook and classification (Vol. 1). Oxford University Press.

Proctor, C., Tsukayama, E., Wood, A. M., Maltby, J., Eades, J. F., \& Linley, P. A. (2011). Strengths gym: The impact of a character strengths-based intervention on the life satisfaction and wellbeing of adolescents. The Journal of Positive Psychology, 6(5), 377-388. 
Qualter, P., Whiteley, H. E., Hutchinson, J. M., \& Pope, D. J. (2007). Supporting the development of emotional intelligence competencies to ease the transition from primary to high school. Educational Psychology in Practice, 23(1), 79-95.

Quayle, D., Dziurawiec, S., Roberts, C., Kane, R., \& Ebsworthy, G. (2001). The effect of an optimism and lifeskills program on depressive symptoms in preadolescence. Behaviour Change, 18(4), 194-203.

Quinlan, D. M., Swain, N., Cameron, C., \& Vella-Brodrick, D. A. (2015). How 'other people matter' in a classroom-based strengths intervention: Exploring interpersonal strategies and classroom outcomes. The Journal of Positive Psychology, 10(1), 77-89.

Rivers, S. E., Brackett, M. A., Reyes, M. R., Elbertson, N. A., \& Salovey, P. (2013). Improving the social and emotional climate of classrooms: A clustered randomized controlled trial testing the RULER approach. Prevention Science, 14, 77-87.

Rooney, R., Hassan, S., Kane, R., Roberts, C. M., \& Nesa, M. (2013). Reducing depression in 9-10 year-old children in low SES schools: a longitudinal universal randomized controlled trial. Behaviour research and therapy, 51(12), 845-854.

Rose, H., Miller, L., \& Martinez, Y. (2009). “FRIENDS for Life”: the results of a resilience-building, anxietyprevention program in a Canadian elementary school. Professional School Counseling, 12(6), 400-407.

Rozendaal, J. S., Minnaert, A., \& Boekaerts, M. (2005). The influence of teacher perceived administration of self-regulated learning on students' motivation and information-processing. Learning and Instruction, 15(2), 141-160.

Ruiz-Aranda, D., Castillo, R., Salguero, J. M., Cabello, R., Fernández-Berrocal, P., \& Balluerka, N. (2012a). Short-and midterm effects of emotional intelligence training on adolescent mental health. Journal of Adolescent Health, 51(5), 462-467.

Ruiz-Aranda, D., Salguero, J. M., Cabello, R., Palomera, R., \& Berrocal, P. F. (2012b). Can an emotional intelligence program improve adolescents' psychosocial adjustment? results from the INTEMO project. Social Behavior and Personality: an international journal, 40(8), 1373-1379.

Rusk, R. D., \& Waters, L. E. (2013). Tracing the size, reach, impact, and breadth of positive psychology. The Journal of Positive Psychology, 8(3), 207-221.

Rusk, R. D., \& Waters, L. (2015). A psycho-social system approach to wellbeing: Empirically deriving the five pathways of positive functioning. The Journal of Positive Psychology, 10(2), 141-152.

Rusk, R., Vella-Brodrick, D., \& Waters, L. (2017). A complex dynamic systems approach to lasting positive change: The Synergistic Change Model. Journal of Positive Psychology. Available first on-line.

Ryff, C. D., Love, G. D., Essex, M. J., \& Singer, B. (1998). Resilience in adulthood and later life. In Handbook of aging and mental health (pp. 69-96). Boston: Springer.

Sawyer, M. G., Pfeiffer, S., Spence, S. H., Bond, L., Graetz, B., Kay, D., et al. (2010). School-based prevention of depression: a randomised controlled study of the beyondblue schools research initiative. Journal of Child Psychology and Psychiatry, 51(2), 199-209.

Schinke, S. P., Schilling, R. F., \& Snow, W. H. (1987). Stress management with adolescents at the junior high transition: An outcome evaluation of coping skills intervention. Journal of human stress, 13(1), 16-22.

Schnitzer, G., Andries, C., \& Lebeer, J. (2007). Usefulness of cognitive intervention programmes for socioemotional and behaviour problems in children with learning disabilities. Journal of Research in Special Educational Needs, 7(3), 161-171.

Schonert-Reichl, K. A., \& Lawlor, M. S. (2010). The effects of a mindfulness-based education program on pre-and early adolescents' wellbeing and social and emotional competence. Mindfulness, 1(3), 137-151.

Schunk, D. H. (1990). Goal setting and self-efficacy during self-regulated learning. Educational Psychologist, 25(1), 71-86.

Sedlmeier, P., Eberth, J., Schwarz, M., Zimmermann, D., Haarig, F., Jaeger, S., \& Kunze, S. (2012). The psychological effects of meditation: A meta-analysis. Psychological bulletin, 138(6), 1139.

Seligman, M. E. P. (2011). Flourishing. A new understanding of happiness and wellbeing-and how to achieve them. Boston: Nicholas Brealey.

Seligman, M. (2018b). The hope circuit: A psychologist's journey from helplessness to hope. New York: Hachette Books.

Seligman, M. E., \& Alder, A. (2018). Positive Education. Global Happiness Policy Report. Global Happiness Council. New York: Sustainable Development Solutions Network.

Seligman, M. E. P., Kaslow, N. J., Alloy, L. B., Peterson, C., Tanenbaum, R. L., \& Abramson, L. Y. (1984). Attributional style and depressive symptoms among children. Journal of Abnormal Psychology, 93(2), 235-238.

Seligman, M. E., Ernst, R. M., Gillham, J., Reivich, K., \& Linkins, M. (2009). Positive education: Positive psychology and classroom interventions. Oxford Review of Education, 35(3), 293-311. 
Senécal, J., Loughead, T. M., \& Bloom, G. A. (2008). A season-long team-building intervention: Examining the effect of team goal setting on cohesion. Journal of Sport and Exercise Psychology, 30(2), 186-199.

Shankland, R., \& Rosset, E. (2017). Review of brief school-based positive psychological interventions: A taster for teachers and educators. Educational Psychology Review, 29(2), 363-392.

Shochet, I. M., Dadds, M. R., Holland, D., Whitefield, K., Harnett, P. H., \& Osgarby, S. M. (2001). The efficacy of a universal school-based program to prevent adolescent depression. Journal of clinical child psychology, 30(3), 303-315.

Shoshani, A., Steinmetz, S., \& Kanat-Maymon, Y. (2016). Effects of the Maytiv positive psychology school program on early adolescents' wellbeing, engagement, and achievement. Journal of school psychology, $57,73-92$.

Slemp, G. R., Tan-Chyuan, C., Kern, M. R., Siokou, C., Loton, D., Oades, L., Vella-Brodrick, D. A., \& Waters, L. (2017). Positive education in Australia: Practice, measurement, and future directions. In In Social and Emotional Learning in Australia and the Asia-Pacific (pp. 98-106). Singapore: Springer Nature.

So, K. T., \& Orme-Johnson, D. W. (2001). Three randomized experiments on the longitudinal effects of the Transcendental Meditation technique on cognition. Intelligence, 29(5), 419-440.

Steiner, N. J., Sidhu, T. K., Pop, P. G., Frenette, E. C., \& Perrin, E. C. (2013). Yoga in an urban school for children with emotional and behavioral disorders: A feasibility study. Journal of Child and Family Studies, 22(6), 815-826.

Stoeger, H., \& Ziegler, A. (2008). Evaluation of a classroom based training to improve self-regulation in time management tasks during homework activities with fourth graders. Metacognition and Learning, 3(3), 207-230.

Thomas, N., Powell, A., Graham, M., \& Fitzgerald, R. (2016). Conceptualisations of children's wellbeing at school: The contribution of recognition theory. Childhood, 23, 506-520.

Warner, T. Q. (2005). Awareness and cognition: The role of awareness training in child development. Journal of Social Behavior and Personality, 17(1), 47.

Waters, L. (2011). A review of school-based positive psychology interventions. The Educational and Developmental Psychologist, 28(2), 75-90.

Waters, L. (2017) Progressing Positive Education and creating Visible Wellbeing. In S. Donaldson \& M. Rao (Eds.). Scientific Advances in Positive Psychology. (Chapter 9; pp. 229-256). Praeger Publishing.

Waters, L., Barsky, A., Ridd, A., \& Allen, K. (2015). Contemplative education: A systematic, evidence-based review of the effect of meditation interventions in schools. Educational Psychology Review, 27(1), 103-134.

Waters, L., Sun, J., Rusk, R., Cotton, A., \& Arch, A. (2017). Positive education. In M. Slade, L. Oades, \& A. Jarden Wellbeing (Eds.), Recovery and Mental Health (pp. 245-264). London: Cambridge University Press.

Weigand, D., \& Burton, S. (2002). Manipulating achievement motivation in physical education by manipulating the motivational climate. European Journal of Sport Science, 2(1), 1-14.

White, M. (2016). Why won't it Stick? Positive Psychology and Positive Education. Psychology of Wellbeing, 6(1), 2.

White, M., \& Kern, M. (2018). Positive Education: Learning and teaching for wellbeing and academic mastery. International Journal of Wellbeing, 8(1), 1-17.

White, M. A \& Murray M. A (2015) (Eds.), Evidence-Based Approaches in Positive Education: Implementing a Strategic Framework for Wellbeing in Schools (p. 10). Netherlands: Springer. doi: https://oi. org/10.1007/978-94-017-9667-5

White, M., \& Waters, L. (2014). The Good School: a case study of the use of Christopher Peterson's work to adopt a strengths-based approach in the classroom, chapel and sporting fields. Journal of Positive Psychology (on-line).

Wood, W., \& Neal, D. T. (2007). A new look at habits and the habit-goal interface. Psychological Review, 114(4), 843-863.

Wyman, P. A., Cross, W., Brown, C. H., Yu, Q., Tu, X., \& Eberly, S. (2010). Intervention to strengthen emotional self-regulation in children with emerging mental health problems: Proximal impact on school behavior. Journal of abnormal child psychology, 38(5), 707-720.

Zylowska, L., Ackerman, D. L., Yang, M. H., Futrell, J. L., Horton, N. L., Hale, T. S., et al. (2008). Mindfulness meditation training in adults and adolescents with ADHD: a feasibility study. Journal of Attention Disorders, 11(6), 737-746.

Publisher's Note Springer Nature remains neutral with regard to jurisdictional claims in published maps and institutional affiliations. 